\title{
Additives in Wood Products-Today and Future Development
}

\author{
Dick Sandberg
}

\begin{abstract}
Most wood products include additives. They may be preservatives to protect the wood against biological degradation or against fire, coatings for protection or to give the wood a more favourable aesthetic appearance, non-wood materials to improve the performance of the product and overcome weaknesses in the wood material, or plastics in combinations with wood residues to create new types of wood-plastic combinations. The global wood industry is, for example the largest user of adhesives; about $80 \%$ of all wood and wood-based products involve some form of bonding and $70 \%$ of the total volume of adhesives produced is consumed in the woodworking industry. Wood can thus be regarded as a composite consisting of wood-based materials combined with other materials to form an aggregate material. An example is plywood, in which veneers are joined with adhesive to form a flat panel. Other types of wood composites include various board products, structural composite timber and, furniture and joinery components, all including some form of bonding with adhesive. This situation obviously influences the way in which we should relate to wood products and their environmental impacts. This chapter gives a state-of-the-art presentation of different additives currently being used in wood products. This information is necessary for further studies on the influence that these additives have on the service life and on environmental aspects, and the limitations which they may impose on the reuse, recycling and upgrading of wood products.
\end{abstract}

Keywords Adhesives - Chips - Engineered wood products - Fibres - Modified wood $\cdot$ Particles $\cdot$ Strands $\cdot$ Surface treatments $\cdot$ Veneer

D. Sandberg $(\bowtie)$

Wood Science and Engineering, Luleå University of Technology,

93187 Skellefteå, Sweden

e-mail: dick.sandberg@ltu.se

(C) Springer Science+Business Media Singapore 2016

A. Kutnar and S.S. Muthu (eds.), Environmental Impacts of Traditional

and Innovative Forest-based Bioproducts, Environmental Footprints

and Eco-design of Products and Processes, DOI 10.1007/978-981-10-0655-5_4 


\section{Introduction}

Since the dawn of civilization, wood has been used in its natural state because of its unique advantages: widespread availability, natural renewal, favourable ecological assessment and flexibility of implementation. Although in the last 150 years we have witnessed an ever-increasing dependence on steel and concrete in structural applications, wood remains an important feature of our infrastructure and one of the few truly renewable resources available to us. Only recently has wood been developed to form a range of products that are increasingly functional, based on a combination of performance and sustainability requirements. This has been possible because of new industrial processes which extend the size and modify the properties of natural wood, and the need to use manufacturing residues and lower grade trees to produce more versatile and more consistent products. The result is a vast array of materials known as engineered wood products (EWPs).

To transform wood into an industrially manufactured engineering material it is necessary in a refining process to combine this natural material with other materials or substances with a broad range of origins, here referred to as additives. This chapter gives an introduction to the additives commonly used in the wood mechanical industry, i.e. the industry which turns the forest into sawn timber, semi-finished products, packaging, construction wood, furniture and interior fittings and in the board industry. The focus is on substances added to the wood either to bond pieces of wood together to change their dimensions or shape or to improve the properties of the wood. Some practical aspects on recycling and the combustion of wood products close the chapter. First, however, an introduction is given to EWPs and the additives that are used in these products.

\section{Additives in EWPs}

EWPs, also referred to as reconstituted wood, wood-based products or wood-based composites, are wood components in general and structural components for industrial use in the production of furniture, in interior and exterior joinery and in building construction. They have in common well-defined dimensions and properties that satisfy a particular need. This family of wood products differs from ordinary sawn timber in the way in which it is further processed to create the "engineering properties". This apparently means that stress-graded sawn timber should be included in this group of wood products, but this is not the case. Wood composites have in general poorer mechanical properties than sawn timber in the longitudinal direction but, because of their more consistent properties in both planar directions and in the cross section of the composite, the safety margins can be kept narrower than when sawn timber is used.

For simplicity in this chapter, this impressive range of wood products is simply designated EWPs. EWPs are a practical way to achieve large structural member 
sizes, far beyond those available with single pieces of timber. In addition, such composite materials can be engineering to be much stronger, stiffer and more dimensionally stable than solid wood by dividing and randomizing defects, densifying the material and strategically placing higher and lower quality materials in high and low stress locations, respectively. With imaginative design and the use of engineered materials, it is possible to create large wooden buildings, for industrial, institutional and residential uses.

Wood itself is a cellular biopolymer composite consisting of cellulose, hemicelluloses, lignin, extractives and inorganics. The three macromolecular cell-wall components of wood play specific roles in determining the properties of the wood cell wall. The cellulose microfibril provides the tensile reinforcement of the wood cell wall, with an exceedingly high tensile modulus of elasticity, of the order of $145 \mathrm{GPa}$. However, although strong in tension, cellulose microfibrils buckle easily when subjected to a compressive load. Lignin provides a rigid enveloping matrix for the microfibril and provides resistance to compressive loads. The surface of the microfibril is highly polar, with a high density of hydroxyl groups on the surface, but the lignin matrix has a much lower density of hydroxyl groups, and this leads to a low adhesive interaction and hence poor interfacial stress transfer between the microfibril and lignin. One role of the hemicelluloses is to act as an interfacial coupling agent between the surface of the microfibril and the lignin matrix.

Nature is programmed to recycle wood back into its basic components of carbon dioxide and water through various degradation mechanisms, including biological, photochemical, thermal, aqueous, chemical and mechanical degradation. To customize or improve its natural properties the better to fit the environment in which it will be used, wood is often combined with natural or synthetic substances such as adhesives, coatings and preservatives or is mechanically joined with nails, screws, bolts, snaps, notched metal strips, etc. For example, glued laminated timber (GLT) has been used for approximately a century to give constructions with properties better than those of sawn timber. Other structural wood-based materials are wood composites, where wood is used in a fractionated form. The application of a coating is the best-known way of changing the characteristics of a wood surface, with regard to both appearance and its mechanical properties such as hardness and abrasive resistance.

One of the key features in wood processing is to change the dimensions of the wood material from "tree dimensions" to an engineered material with properties and dimensions adapted to the purpose for which it is to be used. Figure 1 shows the principal ways that are currently being used in industry to convert trees to wood products. After the forest is harvested, the trees are sorted into different classes depending on their intended use. To produce wood for construction purposes, sawmilling is today the dominant process, yielding sawn timber in well-defined dimensions as well as by-products such as bark, sawdust and chips. An alternative process is the production of veneers for subsequent use for board manufacture (plywood), elements for construction purposes (laminated veneer lumber) or the manufacture of moulded products (laminated veneer products) and high-density materials for interior and special applications (high-pressure laminated veneer). 


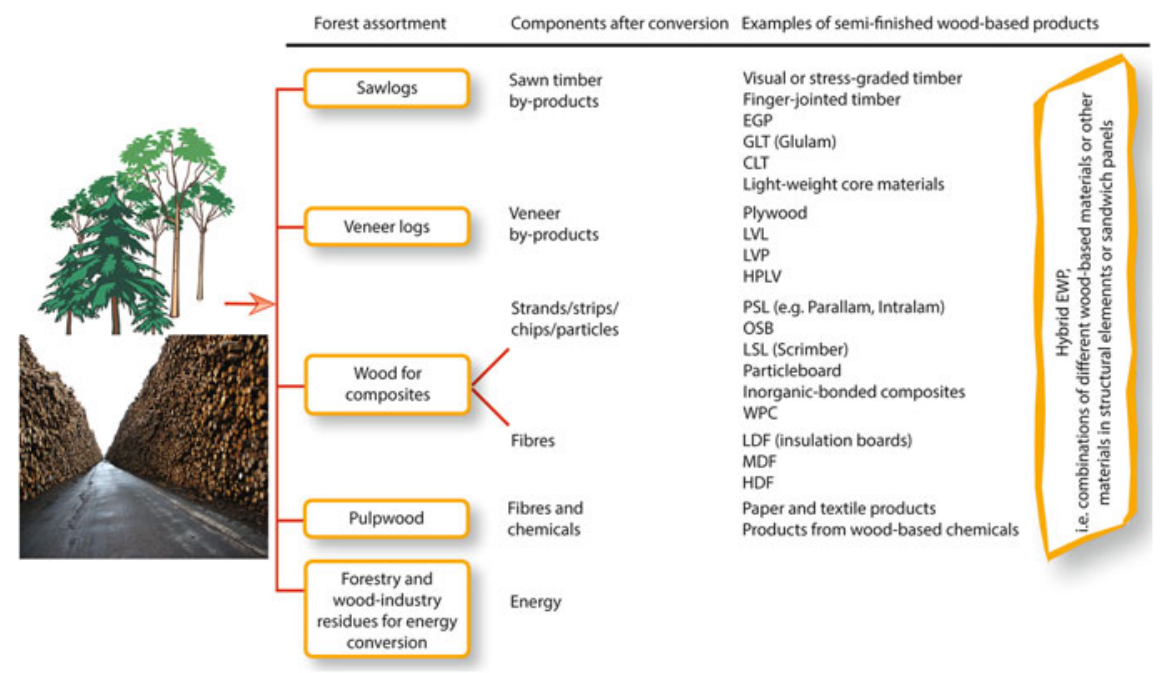

Fig. 1 The industrial use of the forest resource. Depending on species, dimensions and categories, the forest raw material is after harvesting sorted into different classes according to their industrial use. EGP edge-glued panels, $G L T$ glued-laminated timber, $C L T$ cross-laminated timber, $L V L$ laminated veneer lumber, $L V P$ laminated veneer products (moulded products), HPLV high-pressure laminated veneers, $L D F / M D F / H D F$ low/medium/high-density fibreboards, $P S L$ parallel strand lumber, $O S B$ oriented strand boards, $L S L$ laminated scrimbed lumber, WPC wood plastic composites

After the transformation of the tree in the sawmill, the sawn timber does not usually have the dimensions required in the final product, and a lot of effort is being made in the wood industry to transform the sawn timber into dimensions and grades that suit the products requested by the consumers. Joining wood is a major step in these processes, and adhesives of different types are here as the key component.

Trees or parts of trees that are not suitable for use in the sawmill or in veneer processes have, if used for industrial purposes at all, three main uses: for paper pulp production, for the manufacture of wood-based composites or for energy conversion. These processes also use the by-products from the sawmill and veneer processes or residues from other woodworking industries, and in some cases also agricultural waste. The board industry produces a variety of wood-based panel products (oriented strand board, flake board, particleboard, hardboard, insulation board, medium-density fibreboard, cement-bonded board, etc.) based on comminuted wood in different sizes from long and thin flakes (veneer flakes) to fibre bundles that are commonly bonded together by an adhesive or by integral bonding achieved by interfelting of the fibres and in some cases by a ligneous bond. Other materials may be added to improve certain board properties. Wood plastic composites (WPC) are a rather new building material on the market, based on a thermoplastic matrix and a wood component. The matrix is usually recycled polyethylene or polypropylene, and the wood is sawdust or shaving residues from the wood industry (Carus and Gahle 2008). 
EWPs also include structural elements where semi-finished wood-based components are combined to form products such as I-joists, in some cases in combination with other materials. The large variety of sandwich panels is other examples of these hybrid EWPs that can be found on the market, where the engineered properties or functions are even more specific than those of the semi-finished EWPs. Due to the almost unmanageable number of varieties of hybrid EWPs, we shall not provide any deep description of these materials in this section.

The pulp and paper processes and energy conversion based on forestry and wood industry residues are outside the scope of this presentation and are omitted. For more basic studies of these subjects, further reading in Ek et al. (2000) and Hood et al. (2011) is recommended.

A characteristic of EWPs is that, regardless of the dimensions and shape of the wood raw material (from fibres to sawn timber), the wood in a EWP almost always bonded together with an adhesive. Only in the case of insulating boards and fibreboards manufactured by the wet process and self-bonded veneer boards is no adhesive or other binder added in the production process. The variety of properties of EWPs is very large and it is beyond the scope of this survey to give a detailed description them all. Below is a brief description of the most common EWPs (according to Fig. 1) and fibre-reinforced wood with a focus on the additives.

\subsection{EWPs Based on Sawn Timber}

EWPs based on sawn timber are lengthwise joined sawn timber, edge-glued panels (EGP), glued-laminated timber (GLT) and cross-laminated timber (CLT).

\subsubsection{Lengthwise Joining of Sawn Timber}

Lengthwise joining of sawn timber is performed for several reasons, the most common being: (1) to make use of wood waste from, e.g. length adaptation of sawn timber, (2) to achieve length longer than that of the log and (3) to remove defects and increase the strength or to influence the appearance of the sawn timber. Because of the small surface area of the cut surface (the cross-sectional area of the timber) only low tensile forces can be transmitted by simply butt-jointing the ends of the sawn timber. Different methods for joining sawn timber have therefore been developed, and Fig. 2 shows some of them. Today, the most common method for joining sawn timber industrially is finger-jointing.

Finger-jointed timber is used for structural members such as studs and in glulam (GLT), as well as for non-structural purposes. In species in which short clear lengths of wood are separated by knot whorls, it occurs that all defects, mostly knots, are cut away and the clear pieces of sawn timber are finger-jointed to specific ready-to-use components. 
(a)

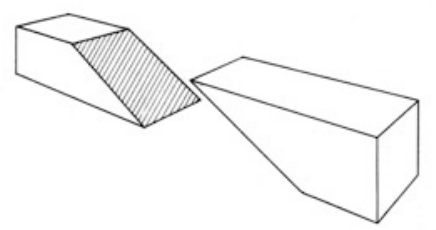

(c)

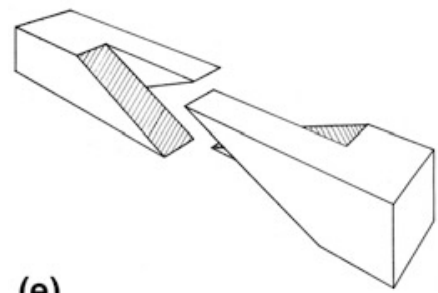

(e)

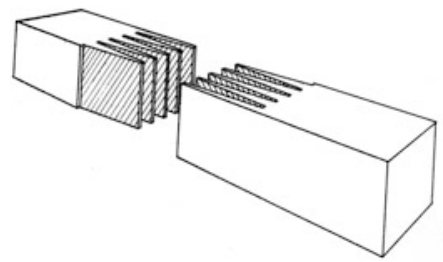

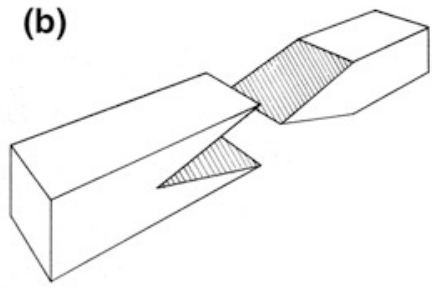

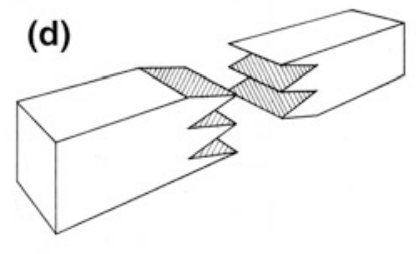

Fig. 2 Different principles for lengthwise joining of sawn timber: (a) simple scarf joint, (b) wedge tenon, (c) "American" scarf joint, (d) multiple wedge tenon and (e) finger-joint

The choice of adhesive in finger-jointing depends on the final use of the product. For structural purposes phenol-resorcinol-formaldehyde (PRF) or melamineurea-formaldehyde (MUF) types are commonly used, and for non-structural products polyvinylacetate (PVAc) or hot melting adhesive are used, but other types of adhesives are also frequently used for joining sawn timber in the industry.

\subsubsection{EGP-Edge-Glued Panels}

An edge-glued panel is a board of widthwise glued lamellae of solid wood. The lamellae are sometimes joined lengthwise, especially in panels of lower grade timber. EGPs are used for furniture, for exterior and interior joinery purposes, or as core for sandwich panels with outer sheets of other wood or non-wood material. The lamellae and the outer sheet are glued with adhesives of various types depending on the properties asked for in the application. EGPs are produced with three levels of adhesive bond quality: (1) interior adhesives that are non-moisture resistant, (2) intermediate moisture resistant adhesives, i.e. lower resistance to moisture than exterior but greater than interior adhesives and (3) exterior adhesives 
that are moisture resistant. Minimum requirements for each type, developed from the results of long-term exposures, are detailed in product standards for EGPs. The most common adhesives in EGPs for interior usage are different types of PVAc adhesives. The amount of adhesive per unit area of bond-line surface is 100 $200 \mathrm{~g} / \mathrm{m}^{2}$. The manufacture of EGPs ranges from manual carpenter-made panels to highly industrialized processes in specialized production units.

\subsubsection{GLT-Glued-Laminated Timber}

GLT, commonly referred to as glulam, is a structural element made of sawn timber glued together with parallel fibre orientation to straight beams or members with some kind of curvatures. In Europe, and also in other parts of the world, GLT is used in a wide variety of applications, ranging from supporting beams in residential framing to major structural elements in non-residential buildings as girders, columns and truss members. Softwood and hardwood species are being used in GLT, but the most common species for GLT production are Norway spruce, Douglas fir, larch, Scots pine, southern pine, radiata pine and yellow poplar. For structures that are expected to be exposed to the prolonged influence of moisture, preservative-treated sawn timber is used. The major advantage of GLT is its high strength and stiffness, which makes it possible to manufacture structures for wide spans and enhanced bearing capacity.

The manufacture of GLT is very similar, regardless of factory and country. Figure 3 shows the principal stages in the manufacture of GLT. Stress-graded sawn timber is general. The cross section of the GLT can be built up from lamellae with approximately the same strength, so-called homogeneous glulam. In order to utilize the timber's strength in the best way, high-strength sawn timber is used for the outer parts of the beam where the stresses are highest, so-called combined glulam.

In GLT manufacture, only adhesives that have a documented high strength and durability under long-term loads are used, and only those adhesive for which the producers have a long practical experience. The different adhesives that can be used for GLT are well regulated and under constant control. In Europe, the formal requirements are given by the European standard EN-301 (CEN 2013) which classifies two types of adhesives, type I and II. The type I adhesives can be used in all climates, while adhesive of type II have restrictions limiting where they can be used.

The traditional and very common adhesives used in the manufacture of GLT are those of the synthetic two-component PRF type (phenol-resorcinol-formaldehyde). All PRF adhesives used for GLT production are of type I. PRF adhesives give a dark reddish-brown bond line.

MUF (melamine-urea-formaldehyde) adhesives are now being increasingly used. MUF adhesives also being type I. The bond lines of MUF adhesives are initially bright but darken over time.

For finger-jointing of lamellae, PFR or MUF adhesives are used. Finger joints can appear as dark spots or thin lines on the GLT surfaces. The labelling of the GLT will specify the type of adhesive used in the production, i.e. type I or II according to EN-301 (CEN 2013). 

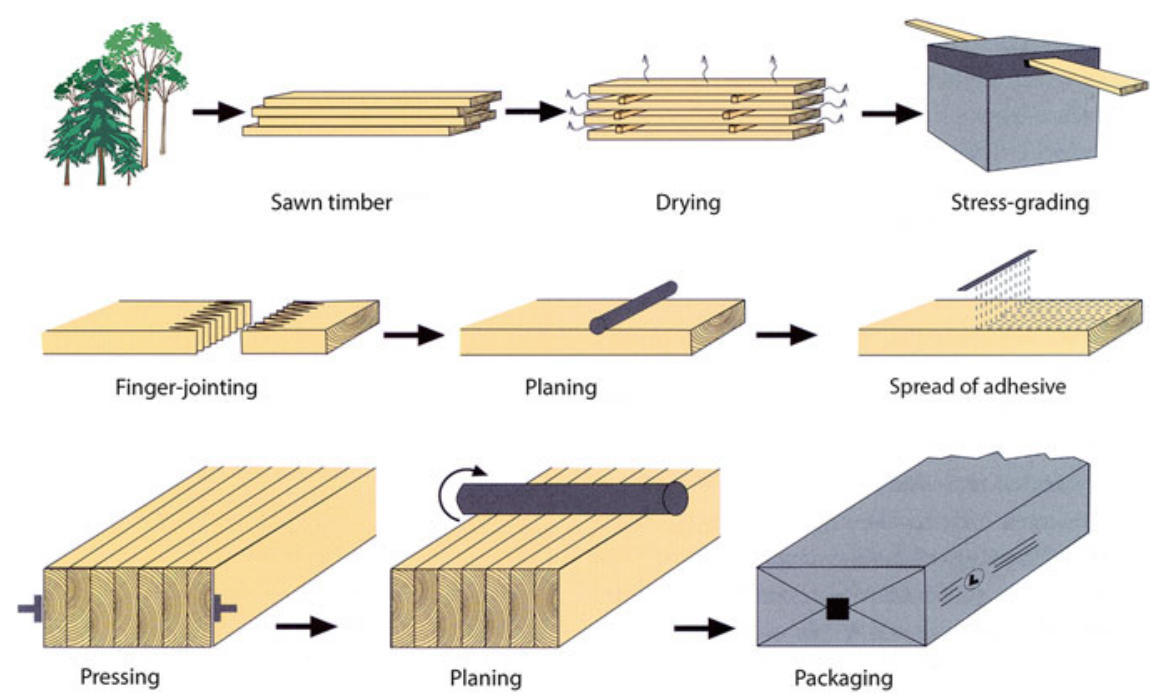

Fig. 3 The main steps in manufacture of glued-laminated timber (GLT)

There is a continuous development of adhesives for GLT, and new adhesives are gradually being introduced. An example of an adhesive recently approved is the single-component polyurethane (PU) adhesive (type II).

\subsubsection{CLT-Cross-Laminated Timber}

CLT, also called X-lam, is a straight or curved, multi-layer timber member consisting of at least three layers, of which at least one of three are orthogonally bonded, which always include timber layers and may also include wood-based panel layers. CLT is a material for the manufacture of structural elements for use in buildings and bridges. CLT can be multi-layered boards normally with a thickness around $70 \mathrm{~mm}$ and consisting of 3,5 or 7 layers or as CLT multi-layered blocks with a thickness of up to $600 \mathrm{~mm}$.

\subsubsection{Lightweight Core Materials}

Lightweight materials based on wood for interior fittings and furniture have been of interest for at least the last 50 years, mainly for cost-reducing reasons. Today, the increasing care of the environment and the growing interest in the concept of a sustainable society provide further impulses for the development of lightweight materials. The main benefits of the lightweight materials for furniture applications are their high strength-to-density ratio. A low weight is advantageous in the transport and handling of products and it also lowers the transportation costs. 
In terms of recycling and resource-efficient material management, lightweight materials made of wood, paper or recycled cellulosic materials have been developed in recent years mainly in the furniture industry. Feifel et al. (2013) have shown that an increased used of lightweight wood-based materials for furniture purposes in general can greatly lower the environmental impact of greenhouse gas emissions, non-methane volatile organic compounds (NMVOC) and formaldehyde from that industry. Lightweight structural materials based on wood and paper layers are being increasingly considered as substitutes for commonly used materials such as fibreboards or particleboards. In terms of recycling and energy consumption, foam and composite cores based on non-renewable resources are, however, critical.

Lightweight materials can be divided according to their function and structure into three groups: (1) lightweight materials which combine materials with a low weight-to-strength/stiffness ratio, (2) structural lightweight materials which are structures mainly for building purposes that, with a minimum of weight, can distribute applied loads and (3) lightweight systems - the superposition of functions of lightweight materials, providing not only supporting functions but also thermal insulation, etc.

During recent years, several ideas for lightweight panels of exclusively solid wood that combine lower weight with high strength have been presented. These panels are mainly for buildings and other structural systems due to their wide range of advantages, i.e. high strength-to-weight ratio, reduction in the cost of framework and good thermal and sound insulation properties (Pokharel 2003). DendroLight is a core material that is available in the market that consists of layers of cross-aligned sawn timber with longitudinal kerfs, which are glued to the surface layer at an angle of $45^{\circ}$ (Berger 2006). Skuratov (2010) has presented a three-layer panel with a core of low-grade sawn timber that has a pattern of hollow cells which reduce its weight. A lightweight panel for the use in furniture construction, for door blanks and for construction of internal wall elements was suggested by the group around Prof. Dick Sandberg in the beginning of the twenty-first century, and is shown in Fig. 4 (Näsström 2005).

\subsubsection{Fibre-Reinforced Wood}

Wood members reinforced with a fibre-reinforced polymer (FRP) composite systems are used in a variety of structural applications, such as GLT for construction (Hallström 1995), GLT for bridges (Dagher et al. 2002; Lopez-Anido and Xu 2002), reinforced railroad ties (Sonti and GangaRao 1996) and the repair of wood piles (Lopez-Anido et al. 2003). Plywood can also be reinforced with fabric, fibres, etc., between the veneer layers. According to Lopez-Anido et al. (2005) there are three procedures to reinforce wood members with FRP composites: (a) wet lay-up of the fabric reinforcement on wood members, (b) adhesive bonding of prefabricated sheets to wood members and c) adhesive infusion, i.e. a variation of the vacuum-assisted adhesive transfer moulding (VARTM) process that applies the Seemann composite adhesive infusion moulding process (SCRIMP), Table 1. 


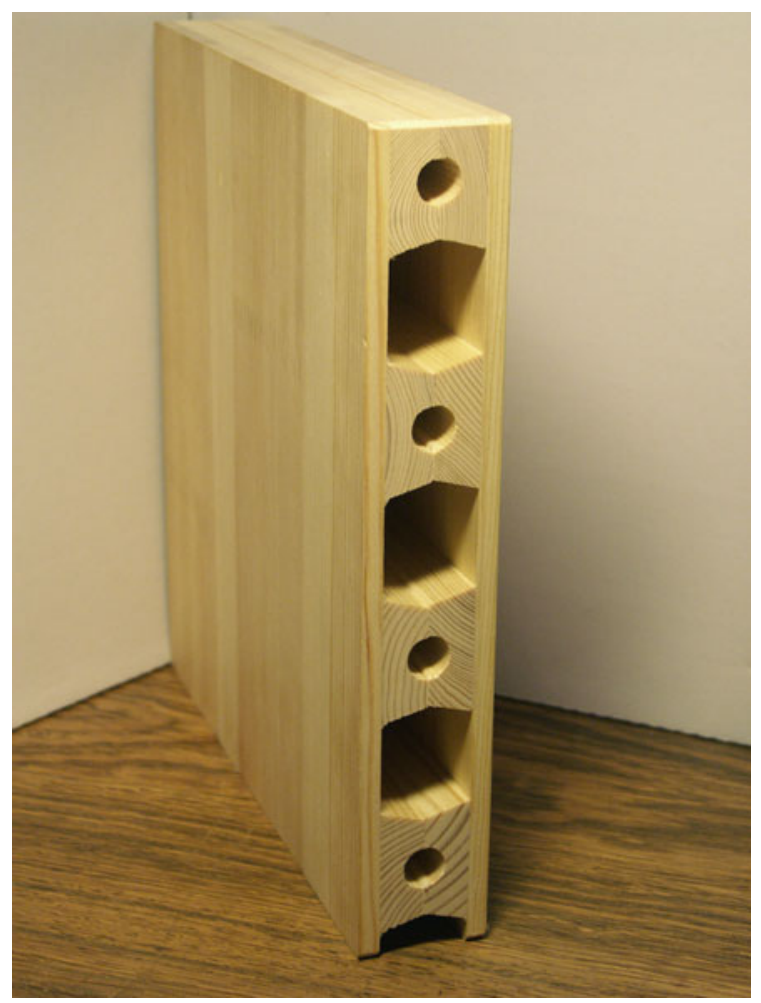

Fig. 4 Example of a lightweight panel manufactured of solid wood. The core elements are cross-laminated to the surface panels. The holes in the core elements are for efficient assembly

Table 1 Hybrid FRP-GLT composite fabrication systems (Lopez-Anido et al. 2005)

\begin{tabular}{l|l|l}
\hline System & Advantages & Concerns \\
\hline Wet lay-up of fabric & $\begin{array}{l}\text { Use of impregnator } \\
\text { Flexible } \\
\text { Ease of use in restricted } \\
\text { areas } \\
\text { Compaction with } \\
\text { vacuum }\end{array}$ & $\begin{array}{l}\text { Quality control } \\
\text { Entrapped air } \\
\text { Compaction and fibre wrinkling } \\
\text { Environmental issues }\end{array}$ \\
\hline $\begin{array}{l}\text { Adhesive bonding of } \\
\text { prefabricated sheets }\end{array}$ & $\begin{array}{l}\text { Reinforcement } \\
\text { prefabrication } \\
\text { Adhesive bonding } \\
\text { Rapid procedure } \\
\text { Ease of fabrication }\end{array}$ & $\begin{array}{l}\text { Shear lag effect } \\
\text { Durability of the adhesive } \\
\text { Two-step fabrication }\end{array}$ \\
\hline $\begin{array}{l}\text { Resin infusion } \\
\text { (VARTM/SCRIMP) }\end{array}$ & $\begin{array}{l}\text { Placement of dry fabric } \\
\text { Infusion under vacuum } \\
\text { High compaction } \\
\text { Fill wood cracks }\end{array}$ & $\begin{array}{l}\text { Fibre wet-out } \\
\text { Difficulty of holding vacuum } \\
\text { Vacuum bag, flow media, and } \\
\text { conduits }\end{array}$ \\
\hline
\end{tabular}


Table 2 General mechanical properties of E-glass fibres (Including E-glass with and without boron oxide)

\begin{tabular}{l|l}
\hline Property & \\
\hline Density $\left(\mathrm{kg} / \mathrm{m}^{3}\right)$ & $2500-2600$ \\
\hline Tensile strength, filament (GPa) & $3.1-3.8$ \\
\hline Tensile modulus, filament (GPa) & $75-80$ \\
\hline Ultimate strain, filament (\%) & $4.5-4.9$ \\
\hline Poisson's ratio & 0.18 \\
\hline
\end{tabular}

The most common reinforcement fibres for wood are glass fibres, but for special applications carbon and aramid fibres can be used. Shade (1998) refers to carbon and aramid fibre reinforcement as "overkill" for wood applications having a very high specific strength and stiffness.

The most suitable reinforcement for a wood construction material is biaxial E-glass because of the orientation of the fibres in two plies (Shade 1998). The layers may be displaced parallel or at an angle of $45^{\circ}$ to the length of the fabric. E-glass fibres are available also in non-woven fabric. E-glass refers to fibreglass produced from a common alumina-borosilicate glass. E-glass composition offers high strength, stiffness, corrosion resistance, low electrical conductivity and essentially isotropic properties. The properties of the E-glass may vary mostly due to a variation in the boron oxide content. The latest commercial needs make it necessary to reduce the boron oxide content in the E-glass composition. Some of the mechanical properties of the E-glass fibres are presented in Table 2.

Thermosetting composite materials form the matrix of the reinforcement. Composites based on thermosetting resins are created when the monomer or pre-polymer liquid is transformed through a chemical reaction into a cross-linked polymer (Wallenberger and Bingham 2010). Thermosetting adhesives are infusible, hard and brittle compared to thermoplastic composites. The requirements of the thermosetting matrix resin used for wood reinforcement are to ensure strong adhesion with a wooden core; to ensure good compensative compression strength for the FRP composite; low weight, reduced costs, a low water absorption rate and reduced environmental hazards. Typical adhesives are unsaturated polyesters, epoxies, vinyl esters, phenolics, PU and silicones.

The fillers are additives in the matrix with a cost reduction purpose. However, some fillers may yield special composite properties. Inorganic fillers such as calcium carbonates, hollow glass spheres and wollastonite are widely used with unsaturated polyester resins.

Release agents are used to prevent a moulded composite from adhering to the surface when curing, i.e. gluing to the pressing moulds. Most popular release agents are sprayed onto the mould surface as a liquid (e.g. silicones), wax or solid film. Polyethylene film can serve as release agent. Release agents can sometimes be mixed with the adhesive to enhance the processing. Common property of the release agents is a low surface energy that hinders the adhesion of the matrix to the mould. The final products will, in this case, contain these substances. 
Fig. 5 Moulded tube from Norway spruce with a length of $250 \mathrm{~cm}$, a diameter of $28 \mathrm{~cm}$, and a thickness of the tube wall of $2 \mathrm{~cm}$, fibre reinforcements: (middle) filament winding of aramid and carbon, (right)

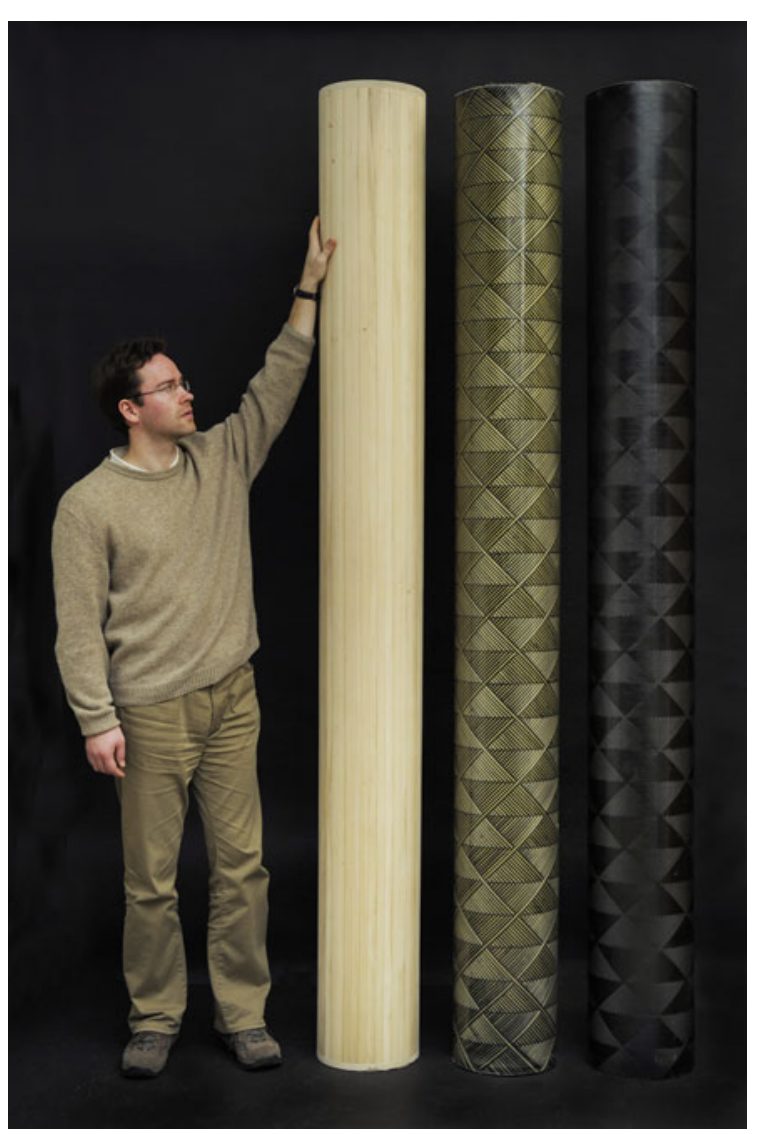

Haller et al. (2013a) suggested a thermo-hydro-mechanical process to manufacture wooden tubes out of sawn timber for load-bearing and conveying applications and they described the implications for construction and the environment, Fig. 4. The tubes were fibre reinforced at the outer face to increase strength and protect the structure. Haller (2007) emphasized that a high load-bearing capacity and a large saving of time and material can be achieved if EWPs are used instead of sawn timber. Haller et al. (2013b) also investigated the use of moulded tubes in aggressive environments. The tubes were fibre reinforced at the outer face, Fig. 5.

As a medium, hot, highly concentrated brine was conveyed at temperatures of up to $60{ }^{\circ} \mathrm{C}$. Compared to steel tubes, the spruce tubes did not show any noticeable erosion after 4 weeks exposure, whereas the steel tubes had been considerably affected. To connect the tubes, fittings made of resin-impregnated Compreg (see Sect. 2.2.4), specifically designed for the purpose were used. In Kutnar et al. (2015) it is shown how the moulded and fibre-reinforced tubes are used for wind turbines, Fig. 6. 


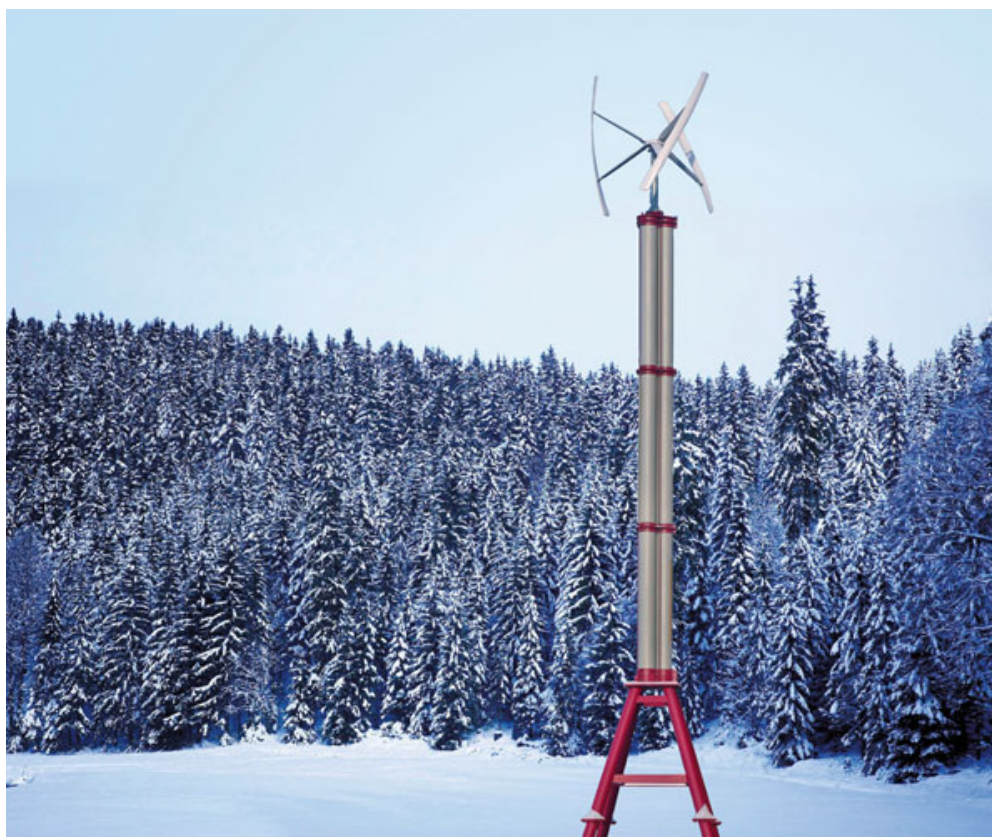

Fig. 6 Wind-power plant from fibre-reinforced moulded tubes

\subsection{EWPs Based on Veneers}

EWPs based on veneers are plywood, laminated veneer lumber (LVL), laminated veneer products (LVP) and high-pressure laminated veneer. They are briefly presented below.

\subsubsection{Plywood}

Plywood is a rigid board composed of an odd number of veneers glued together so that the fibre orientation of the veneer is perpendicular to the fibre orientation of the adjacent veneers. Plywood mills cut veneer for their own production and, after turning, the sheets are cut into the required dimensions. The sheets are dried and glued together in a hot press under high pressure, and are then trimmed, polished and conditioned to the desired moisture content. There are numerous grades, but plywood can be divided into plywood for constructional (exterior) purposes, for interior use (joinery and decorative plywood) and for special application such as concrete shuttering, marine plywood, plywood with special surface layers, etc. Board types where veneer sheets are glued to a timber-strip core, i.e. a core plywood or face-glued blockboard, are also assigned to the group of plywood. 
Additives in plywood are:

- Adhesives for bonding the veneers

- Surface layers or treatments

Plywood is glued with a thermosetting adhesive. Phenol-formaldehyde-based adhesives are used for exterior-type plywood and urea-formaldehyde (UF), reinforced urea adhesives and sometimes natural polyphenols (tannins) mixed with synthetic adhesives are used for interior-type plywood. The spread (amount of adhesive per unit area of bond-line surface) varies from about 100 to $500 \mathrm{~g} / \mathrm{m}^{2}$ depending on several factors pertaining to the wood, adhesive and manner of application.

Plywood panels may be surfaced with metals, plastics, or other material, or their veneers may be impregnated to achieve a superficial hardness, or resistance to micro-organisms, fire or other destructive agents.

\subsubsection{LVL-Laminated Veneer Lumber}

Laminated veneer lumber (LVL and also Microllam LVL) is made of veneers with a thickness between 2 and $4 \mathrm{~mm}$ bonded together with the same fibre orientation in the layers. The manufacturing procedure is very similar to that of plywood production. The different stages in the manufacture of LVL are intended to eliminate the defects inherent in ordinary sawn timber and to develop a higher strength, a good dimensional stability and a homogeneity of physical and mechanical properties along the beam or elements. LVL is in most cases bonded with a phenol-formaldehyde (PF) or melamine-formaldehyde (MF) adhesive, and has a higher strength and stiffness than plywood. LVL can be found in a large variety of dimensions; length up to $25 \mathrm{~m}$, thicknesses below $150 \mathrm{~mm}$ and width up to $2.5 \mathrm{~m}$.

\subsubsection{LVP_Laminated Veneer Products}

LVP consist of veneers bonded together with an adhesive under pressure into a predetermined shape and usually under an elevated temperature to decrease the curing time of the adhesive. The process used to manufacture such products is generally called laminated bending and it is commonly used for the manufacture of components for exterior and interior use.

Different techniques for forming LVPs have been developed during the last hundred years: male and female moulds, pressing lamination to shape by means of metal tension bands or with an inflated flexible rubber hose and a metal strap, etc. Stevens and Turner (1970) give a good overview of the various techniques for forming LVP. The most frequently used industrial method for bending laminated assemblies to the desired shape and applying the requisite pressure to achieve 
proper bonding together of the laminae is to press the assembly in a mould between shaped male and female forms (Navi and Sandberg 2012).

The adhesive is extremely important for the function of the final LVP, and the development of synthetic adhesives has contributed to their development. Common adhesives for the lamination of veneers are based on reactions of formaldehyde with phenol, resorcinol, urea, melamine or a mixture thereof (Rowell 2005). Urea-formaldehyde (UF) adhesives; melamine urea-formaldehyde (MUF) adhesives or emulsion; polymer isocyanate (EPI) adhesives; PU adhesives; and epoxy adhesives are examples of adhesives used for the laminated bending of veneers. Urea-formaldehyde-based adhesives are the adhesives most frequently used in the industry for LVP.

\subsubsection{HPLV—High-Pressure Laminated Veneer, DW—Densified Wood}

High-pressure laminated veneer (HPLV) and densified wood (DW) are wood materials that have been compressed in the transverse direction in order to increase their density. Compression in the transverse direction reduces the void volume of the lumens in the wood material and increases its density. This process is commonly called densification (Sandberg et al. 2013). One of the reasons for densifying wood in the transverse direction is to produce high-quality components from timbers of low quality. However, densified wood has an undesirable property, i.e. a tendency to recover all or part of its compression set and return to its initial dimensions when subjected to heat and humidity. In most of densification processes that have been industrialized, this recovery problem has been solved by the development of adhesive-impregnated products, which are now being commercially produced. Some examples of products that can be found on the market are presented here.

Solid wood treated with a thermosetting, fibre-penetrating adhesive and cured without compression is known as Impreg. The wood is soaked in the aqueous adhesive solution or, if air dry, is impregnated with the solution under pressure until the adhesive content amounts to $25-35 \%$ of the weight of dry wood. The treated wood is allowed to stand under non-drying conditions for 1-2 days to permit a uniform distribution of the solution throughout the wood, and the adhesive-containing wood is then dried at a moderate temperature to remove the water and finally heated at a temperature of $60-150{ }^{\circ} \mathrm{C}$ to cure the adhesive. Very high drying rates should be avoided to prevent excessive migration of the adhesive to the surface. A number of different adhesive-forming systems have been successfully polymerized within the cell walls of wood, namely phenol, resorcinol, melamine- and urea-formaldehydes, phenol furfural, furfuryl aniline and furfuryl alcohol (Stamm and Seborg 1939). 
Compreg is similar to Impreg except that it is compressed before the adhesive is cured within the wood. The adhesive-forming chemicals (usually PF) act as plasticizers for the wood so that it can be compressed to a density of $1200-1350 \mathrm{~kg} / \mathrm{m}^{3}$ at a pressure of about $7 \mathrm{MPa}$ and a temperature of $125-150{ }^{\circ} \mathrm{C}$ (Kollmann et al. 1975).

Electrical transmission support components made from densified wood are typically adhesive-impregnated laminated veneer (Kamke 2013). Low molecular weight adhesives (typically PF) are used to impregnate the veneer, which is then partially cured in an oven. The impregnated wood is compressed in a heated press (open system) to a density of approximately $1300 \mathrm{~kg} / \mathrm{m}^{3}$. Another use for adhesive-impregnated densified veneer is in storage containers for liquid natural gas and associated support structures (wear plates for machinery and transportation vehicles, machine pattern moulds, bullet-proof barriers and some structural building components).

Panzerholz compressed wood (Delignit), is an extremely hard multi-layered sheet material produced in Germany. It is manufactured from beech veneers and synthetic adhesives under heat and a high pressure. Under these conditions the veneers are compressed to half their original thickness. The material is used for security panels, tooling, jigs, moulds, transformer parts, support for liquid natural gas tanks, neutron shielding and audio component cases.

Another product produced in Germany by Deutsche Holzveredelung is Dehonit, a compressed laminated wood manufactured from high-quality selected beech veneers coated or impregnated with a special synthetic phenolic adhesive. It is pressed under high pressure and temperature to form a laminate material.

In France, Permawood, also known as Lignostone, is a laminated densified wood according to the DIN 7707 and IEC 61061 standards (DIN 1979; IEC 2006), made of beech veneers laminated together using synthetic adhesive that harden under pressure and heat.

In the United States, densified wood is on the market under the trade names Permali and Insulam. These materials are densified, phenolic impregnated and laminated products made from beech veneers, and are laminated with cross-directional fibres. The veneers are impregnated under vacuum and then densified through the application of heat and pressure. The result is a homogeneous material with high strength and toughness and excellent dimensional stability and dielectric properties. The product is used for electric power equipment, structural supports in cryoenvironments and electrical insulation for rail transportation vehicles.

In Australia, Insulcul Services Ltd. is producing densified wood manufactured from beech veneers, impregnated with a synthetic adhesive and densified under high pressure and temperature. The veneers are compressed at $90{ }^{\circ} \mathrm{C}$, resulting in a material with uniform strength and stability. The product is used by the electrical power industry.

In Italy, a laminated and densified beech products (RANPREX) is produced by Rancan Srl. The product is impregnated with special thermosetting adhesive and densified at high pressure and temperature. The product is an excellent electrical and thermal insulator, with good physical and mechanical characteristics under 
compression and bending loads and with good impact resistance. The material is also self-lubricating and extremely resistant to wear. It is used for many different applications; it is used in the electrical power distribution industry, for support beams, treaded rods, compression blocks and pressure rings.

Adhesive-impregnated laminated densified wood products are also produced in India by, e.g. Surendra Composites Private Ltd. They produce laminates of adhesive-impregnated veneer, which are used for electrical power transmission equipment and machine parts.

Olympus Corp. in Japan has developed a three-dimensional moulding process for wooden materials in which the density of a piece of cypress wood can be increased from approximately $450 \mathrm{~kg} / \mathrm{m}^{3}$ to more than $1000 \mathrm{~kg} / \mathrm{m}^{3}$. The resulting material is thin enough to be used as a casing material for electronic products, but is much harder than, e.g. ABS plastics and polycarbonate-adhesive-based engineering plastics that are normally used in such applications.

MyWood2 Corporation (Iwakura, Aichi, Japan) manufactures densified solid cedar wood products. Their primary market is flooring in Japan and China and the products are also sold for use in furniture. The MyWood2 product is wood impregnated with a polymer to provide resistance to water, and compressed to approximately $50 \%$ of its original volume.

\subsection{EWPs Based on Strands, Strips, Chips and Particles}

EWPs based on strands, strips, chips and particles include parallel strand lumber, oriented strand boards, laminated scrimbed lumber, particleboards, inorganic-bonded composites and wood-plastic composites.

\subsubsection{PSL_Parallel Strand Lumber}

The manufacture of parallel strand lumber (PSL, also called Parallam) is based on a technology which makes it possible to convert small trees into elements with large cross sections (up to ca. $30 \times 50 \mathrm{~cm}^{2}$ ) and considerable lengths (up to $20 \mathrm{~m}$ ). These products are intended for building construction for elements in compression, large trusses, beams or posts.

PSL is manufactured from parallel-oriented veneer strips, made from rotary cut veneer or veneer waste. After drying to a moisture content of about $6 \%$, the strands are treated with an adhesive with hydrophobic properties and introduced in the longitudinal direction into a continuous press where the adhesive is polymerized by microwaves. After sanding, the PSL is cut into sections ready for use.

PSL is very strong in its primary axis. The strength properties are higher than those of sawn timber. Additional strength is gained from the $10 \%$ densification relative to the original timber density. Strands fail in tension only because the strand 
overlap is large and the resistance to shear is greater than the tensile strength of the strand.

\subsubsection{OSB-Oriented Strand Boards}

Oriented strand boards (OSB) are developed from wood strands which are typically 15-25 mm wide, 75-150 $\mathrm{mm}$ long and 0.3-0.7 mm thick, cut from logs of small diameter. Adhesive is used to bond the strands together and the boards are fabricated under pressure at a high temperature. The strands in the outside layers are aligned parallel to the length, whereas the internal strands are deposited randomly or perpendicular to the face layers. OSB is therefore a multi-layer board, used in a large variety of structures of an industrial or decorative nature. The boards are used for covering floors, ceilings and sometimes walls. The OSBs are also being utilized more and more in packaging, for cases, pallets, etc.

\subsubsection{LSL_Laminated Scrimbed Lumber}

Like PSL, laminated scrimbed lumber (LSL) uses a manufacturing technology which makes it possible to convert small trees into elements with a large cross section, but treetops and branches can also be used. The debarked wood is flattened and partially split in the longitudinal direction using crushing and coarse so-called scrimming rollers, and the dried "scrims" are further processed using fine scrimming rollers to form mats. These mats are in general layered to each other to achieve the thickness and properties required of the final component. The orientation of the mats in LSL is parallel (i.e. the fibre orientation of all the scrims run parallel to each other), perpendicular (i.e. different layers oriented at $90^{\circ}$ to each other) and also mixed, before the mats are laminated together under pressure to a component of beam or panel size. In general a PF adhesive is used.

\subsubsection{PB-Particleboards}

Particleboards (PB) are manufactured from wood particles that have various dimensions, cut mechanically by chippers, flakers, etc., and are in general three-layered. The mechanical properties of the boards depend on the dimensions as well as on the orientation and arrangement of the wood particles used in the board manufacture.

The particleboard industry has been commercialized successfully throughout the world because of the favourable conditions for raw material supply as well as because of market demands. The PB process makes it possible to use wood trunks of small diameters and wood residues. Historically, the availability of raw materials was good and the cost was relatively low. However, this relationship has drastically changed in recent years as a result of competition from the need for biomass fuel. 
(a)

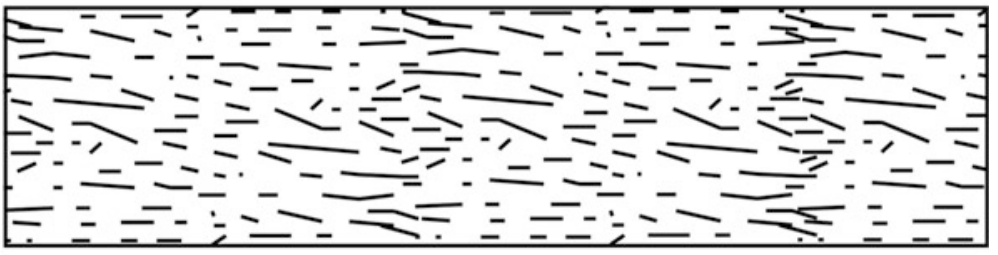

(b)

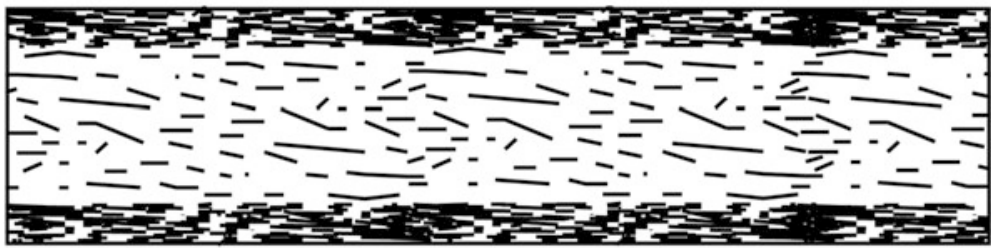

(c)

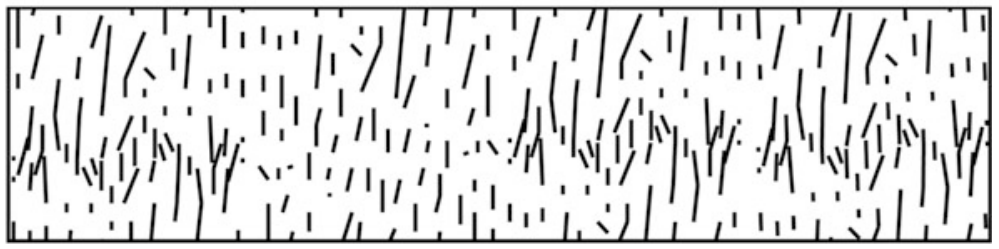

Fig. 7 Diagrammatic presentation of the cross section of particleboards, (a) manufactured by flat hot pressing, the orientation of the particles is parallel to the surfaces and the board is homogeneous (b) manufactured by flat pressing, board with three layers (c) manufactured by extrusion, the orientation of the particles is perpendicular to the board surfaces

Particleboards are very useful in the furnishing and construction industries. The production of particleboards also leads to an effective use of wood with a very small percentage of waste, 10-25\%, instead of 50\% in the sawing of logs.

The manufacture of particleboard is a dry process and there are two different methods of production; flat hot pressing and extrusion, which give different types of boards with different particle orientations. In the first method, the particles are oriented parallel to the panel surface, whereas in the second method the particles are oriented perpendicular to the surface. Figure 7 shows the two types of particleboard and the various stages in their production are illustrated in Fig. 8.

\subsubsection{IBC-Inorganic-Bonded Composites}

The traditional way of creating a wood composite is to blend wood together with an adhesive or a plastic as in WPC, and to press the blend at high heat and pressure. A considerably less used process that in which boards or other types of construction 


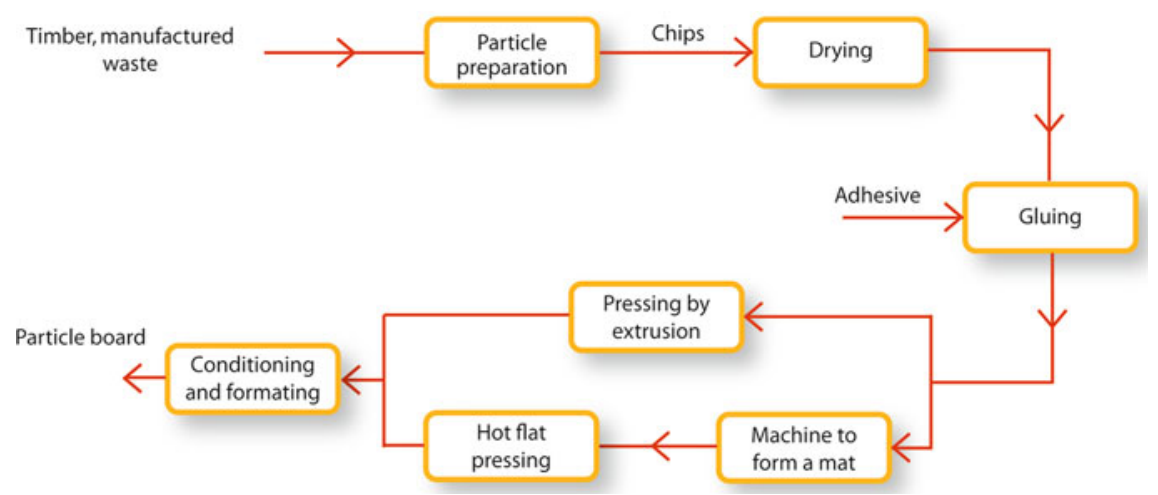

Fig. 8 Diagram of the various stages of the two different methods of manufacturing particleboards, i.e. extrusion and flat pressing

elements are produced from comminuted wood (excelsior, particles or flakes) or other types of fibre of vegetable biomass blended with cement, magnesite $\left(\mathrm{MgCO}_{3}\right)$ or gypsum. However, the most expedient binder giving strength, durability and acoustic insulation properties is Portland cement. In this process heat is not required.

Inorganic-bonded composites (IBC) have a long history that started with commercial production in 1914 in Austria that produced magnesium oxide-bonded wood excelsior boards (Maloney 1977; Geimer et al. 1994). Frybort et al. (2008) give a comprehensive review based on sources from the mid-twentieth century of the mechanical and physical properties of cement-bonded composites.

There are only about 50 mills worldwide making cement-bonded particleboard (CBPB), each of which produces on average only about $200 \mathrm{~m}^{3} /$ day. The woodcement boards are used for specialized structural applications. They have outstanding properties in terms of their reaction to fire, durability, sound insulation and stiffness, which render the product most suitable for internal wall constructions in public places, the lining of lift shafts, the construction of cabling ducts, soffits, motorway acoustic fencing and the cladding of prefabricated house units. The cement-bonded board is harder and more resistant than its components alone, with a lower cost and lower density than concrete (Hein et al. 2009).

Chemical substances, especially extractives, present in the wood may delay or sometimes even impede the cement curing, making it necessary to use some process that increases the chemical compatibility between the wood and the cement (Savastano et al. 2000). Many manufacturers use additives like mica (silicate/phyllosilicate minerals), aluminium stearate and cenospheres (a lightweight, inert, hollow sphere made largely of silica and alumina and filled with air or inert gas) in order to achieve certain board qualities. Typical cement fibreboard is made of 40-60 weight $\%$ of cement, $20-30 \%$ of fillers, 8-10\% of cellulose, $10-15 \%$ of mica. Additives such aluminium stearate and PVA are normally used in 
quantities less than $1 \%$. Cenospheres are used only in low-density boards with quantities between 10 and $15 \%$ (Kuroki et al. 1993).

\subsubsection{WPC-Wood-Plastic Composites}

Although EWPs based on strands, strips, chips and particles have been made with thermosetting adhesives for many years, only in the last three decades has a serious attempt been made to incorporate wood flour and chips into thermoplastic adhesives in order to produce wood-plastic composites (WPC). The term "wood-plastic composite" refers to any composite that contains wood particles and any of the thermosetting or thermoplastic polymers. In contrast to the wood-thermoset composites, wood-thermoplastic composites have seen a phenomenal growth in the United States in recent decades and for this reason they are often referred to simply as wood-plastic composites (WPC) with the understanding that the plastic is always a thermoplastic. New compounding techniques and interfacial treatments utilizing coupling agents make it feasible to disperse high volume fractions of hydrophilic wood in various plastics. These compounds can be continuously extruded, thermoformed, pressed and injection moulded into any shape and size, and they thus have offer the potential to replace natural wood in many applications. A WPC is in principal a composite of wood particles and a thermoplastic, with a dry weight percentage of the wood component typically in the range of 50-60\% (Klyosov 2007). Figure 9 shows an example of the use of a WPC product in Sweden. Today, WPCs are characterized as a building material and they have their main markets in the US (Clemons 2002). The European WPC market is also steadily increasing. In general, WPC products are marketed as a low maintenance building material with a high ability to resist fungal decay, although combinations of wood and polymers often have poor long-term durability when exposed outdoors. A major cause can be insufficient wood-polymer adhesion due especially to an intrinsically low compatibility between the wood substance and the polymers used. Adhesion losses are usually caused by the hygroscopicity of wood and the differences in hygrothermal properties between the components.

\subsection{EWPs Based on Fibres}

Wood fibres can be used to produce a wide variety of low-density three-dimensional webs, mats and fibre-moulded products. Short wood fibres can be blended with long fibres and formed into flexible fibre mats, utilizing physical entanglement, non-woven needling or thermoplastic fibre melt matrix technologies. The most common types of flexible mat are carded, air-laid, needle-punched and thermobonded.

A large number of EWPs based on fibres are developed in the form of panels. Their diversity is large and is increasing, taking advantage of scientific knowledge 
Fig. 9 Example of extruded wood-plastic composite (WPC) profiles for cable channel covers (dark coloured WPC in the rear of the image) and end plugs for bobbins for large paper rolls (front). The WPC profiles are manufactured by Ofk Plast Inc. in Karlskoga and Polyplank Inc. Färjestaden, Sweden

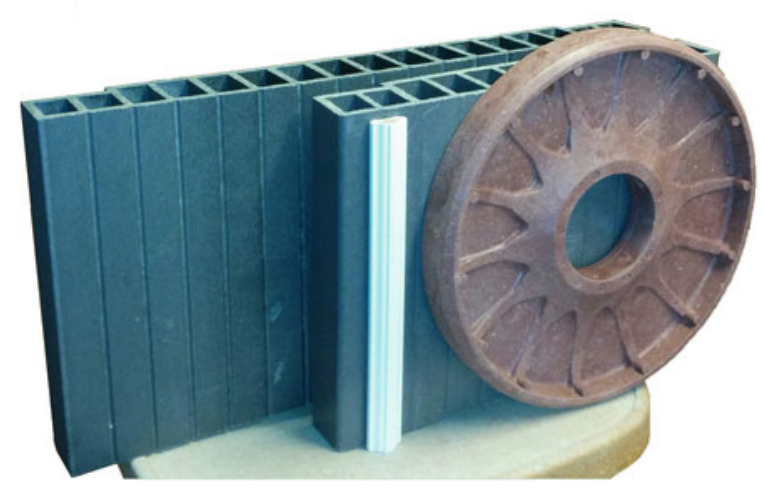

and technological developments in the production field and taking into consideration the increasing requirements imposed on construction materials. The various types of fibreboards derived from wood are insulating fibreboards, and low-density fibreboards (LDF), medium-density fibreboards (MDF) and hardboards or high-density fibreboards (HDF).

The manufacturing processes are divided into two principal classes. In the first class, the cellulose fibres bind together by natural forces (hydrogen bonds). This bonding of the fibres is achieved through drying and compression in a process which takes place in a wet condition, no adhesive being used to bond the fibres together. This process is used to make paper, paperboard, insulating fibreboard, semi-hard boards and hardboards, Fig. 10. In the second class, the process is a dry process where the bonding together of the particles is accomplished by the use of various adhesives, the most widely used adhesives being PF and UF resins.

The panel material containing adhesive, i.e. MDF, is described in the following section.

\subsubsection{MDF-Medium-Density Fibreboard}

The essential difference between hard fibreboards and MDF is that adhesives are used as binder in MDF, whereas in hard fibreboards the lignin, under the effect of pressure and temperature is transformed into a kind of adhesive. The MDF manufacturing process began as a semi-dry process before being developed into fully dry process method. A diagram of the manufacture of MDF is given in Fig. 11 . Since less water is used than in the wet process smaller amounts of polluted water are produced. In addition, this method allows the fabrication of panels with thicknesses from 2 up to $100 \mathrm{~mm}$.

A uniform distribution of fibres during manufacture ensures that the MDF has a homogeneous structure, and it is possible to manufacture MDF boards with different characteristics to suit particular applications. The MDF is a homogeneous product with a density from 600 to $800 \mathrm{~kg} / \mathrm{m}^{3}$. A MDF board is easy to machine 


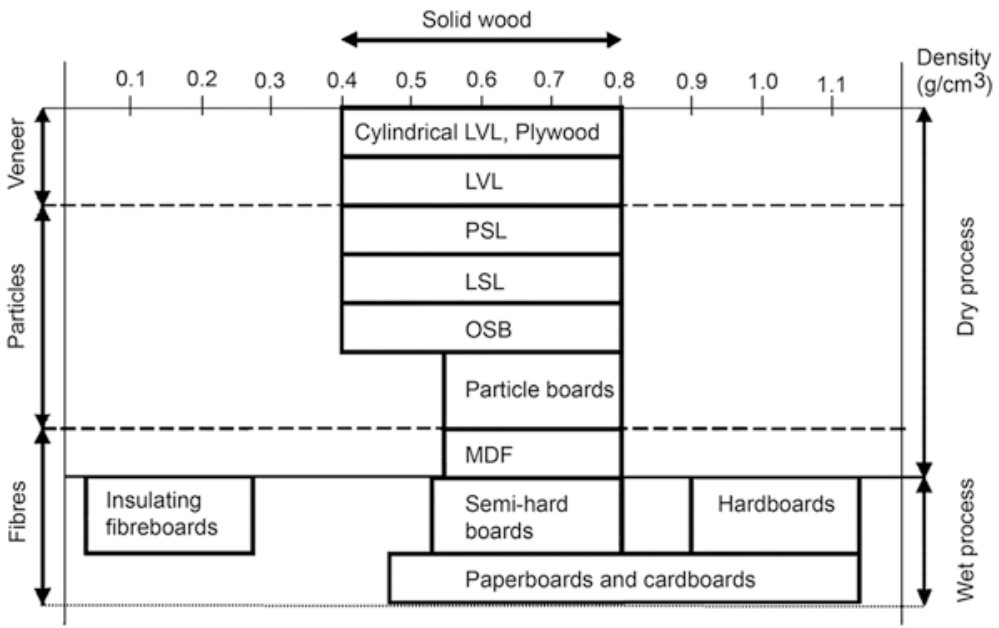

Fig. 10 Classification of panel materials according to the dimensions of the raw material and the manufacturing process (modified from Suchsland and Woodson 1986)

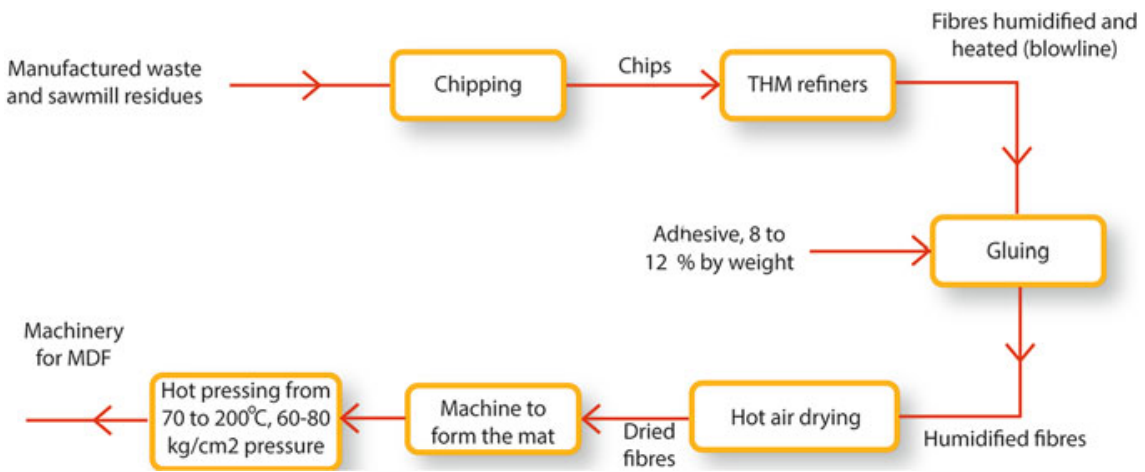

Fig. 11 Diagram of the manufacture of MDF by the dry process

and its regular surface is exceptionally well suited to painting or the application of a decorative coating. It is this quality which has given MDF the place that it occupies in the furniture industry. The thick MDF is used in joinery and for door frames, window frames, etc.

\subsection{Hybrid EWPS}

Hybrid engineered wood products consist of different EWPs or EWPs in combination with other materials. Typical hybrid EWPs are: 
- Sandwich panels, e.g. a core of an insulation material, honeycomb, etc., and outer sheets of a board material such as plywood, OSB or MDF.

- Construction elements such I-joists or ribbed elements.

By combining different materials, the properties of the hybrid EWP can be designed specifically to give, e.g. low weight, high strength or low heat transmission.

\subsection{Joining Members in Timber Engineering}

In wood constructions, different kinds of semi-finished wood-based components are joined together to function as a system. Joints affect the structural behaviour of the elements, e.g. by providing stiff connections or hinges. Traditional joinery techniques have a very long tradition. A comprehensive overview of traditional Japanese, Chinese and European joinery techniques for sawn timber structure has been given by Zwerger (2012), and for constructions and joint techniques from logs by Phleps (1982). Joints in timber structures are in general classified as: traditional timber joints, glued joints and dowelled joints. Glued joints in timber engineering use the same types of adhesives as those used in the manufacture of structural elements like glulam, LVL and finger-jointing for structural purposes (see in the section on adhesives). A waterproof adhesive is strongly recommended as a fastener for wooden structures. Dowelled joints are the most common type of fastener for wood elements, and they transfer forces through shear in mechanical fasteners mounted at an angle to the force direction. The fasteners are made of a ductile steel material, and are designed for a large variety of different functions, Fig. 12. Metal fasteners and connectors can be divided into the following groups:

- Nails, screws, bolts and steel dowels

- Nail plates, punched metal plate fasteners, single- and double-sided tooth plate connectors

- Special connectors of metal plates, steel straps and framing anchors

- Steel rods for the cross-bracing of structures

Metal fasteners and connectors are easy to identify and distinguish from the wood material, and can be separated therefore reuse or before combustion of the recycled wood products (see Sect. 6 below).

The development of wood-to-wood joinery was not in the focus of research for many decades (Schindler 2009), due to the market-dominating position of metal fasteners. The craft sector was facing difficulties when transferring traditional knowledge about the joints load-bearing capacity in a suitable form for engineers and architects like calculation tables and assured load-bearing capacity. Metal fasteners were developed at the beginning of the twentieth century, and in the 1950s 


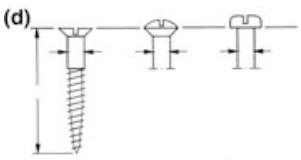

(b)

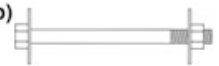

(c)

(a)

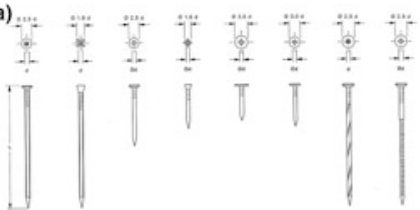

(e)
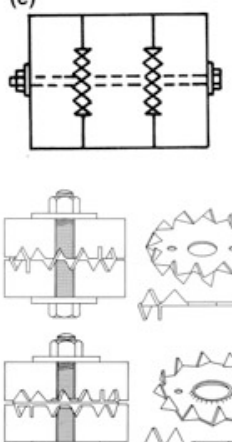

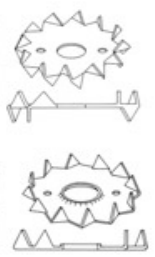

(g)

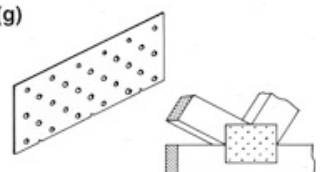

(f)

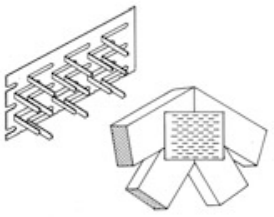

Fig. 12 A selection of timber fasteners and connectors made of metal: (a) nails, (b) bolt, (c) dowel, (d) screws, (e) single-sided toothed plate connector used for a demountable joint (bottom), double-sided toothed plate connector for a permanent joint (middle), and a joint with bolts and connectors (top), (f) punched metal plate, (g) nail plate for hand nailing

a variety of fastener types were offered and were continuously being used to replace traditional wood-to-wood joints (Graubner 1992). With the introduction of CNC technology in the carpenters workshop and the building industry, wood-to-wood joinery regained part of its former position and scientific attention, due to its economic and design potential (Schindler 2009).

One indication for this is the rediscovery of the dovetail joints in the 1990s for robotic manufacturing in Europe and North America. This rediscovery led to a focus on research on this type of joint, which finally resulted in technical approval, e.g. in Germany (DIBt 2012), and the great effort by, e.g. Bobacz (2002), Dietsch (2005), Hochstrate (2000), Holzner (1999), Kreuzinger and Spengler (1999), Tannert et al. $(2007,2011)$ which yielded a lot of understanding and established it for a multitude of applications. Figure 13 shows an example of a new concept for joining timber in construction by Rebstock et al. (2015). This so-called Makerjoint concept uses LVL as nodes in regions with a pronounced non-uniform stress distribution and sawn timber in regions with a more uniform stress distribution. No metal fasteners or adhesives are used in the joint between the timber and the LVL. The development of different wood-to-wood joints with robotic tools yielded designs which show the great potential of wood-to-wood joints. Since then different types of wood-to-wood joints have been used, e.g. in the Tamedia office building and the Sequential pavilion, both in Zürich, Switzerland and in the ICD/ITKE pavilion in Stuttgart, Germany.

Current development and research point towards an increased use of six-axis robots, which resemble a human arm and which were formerly most common in industrial manufacturing contexts. Here, Robeller with co-workers have recently developed snap-fit joints or dovetail joints for shell structures without glue (Robeller et al. 2014a, b). 

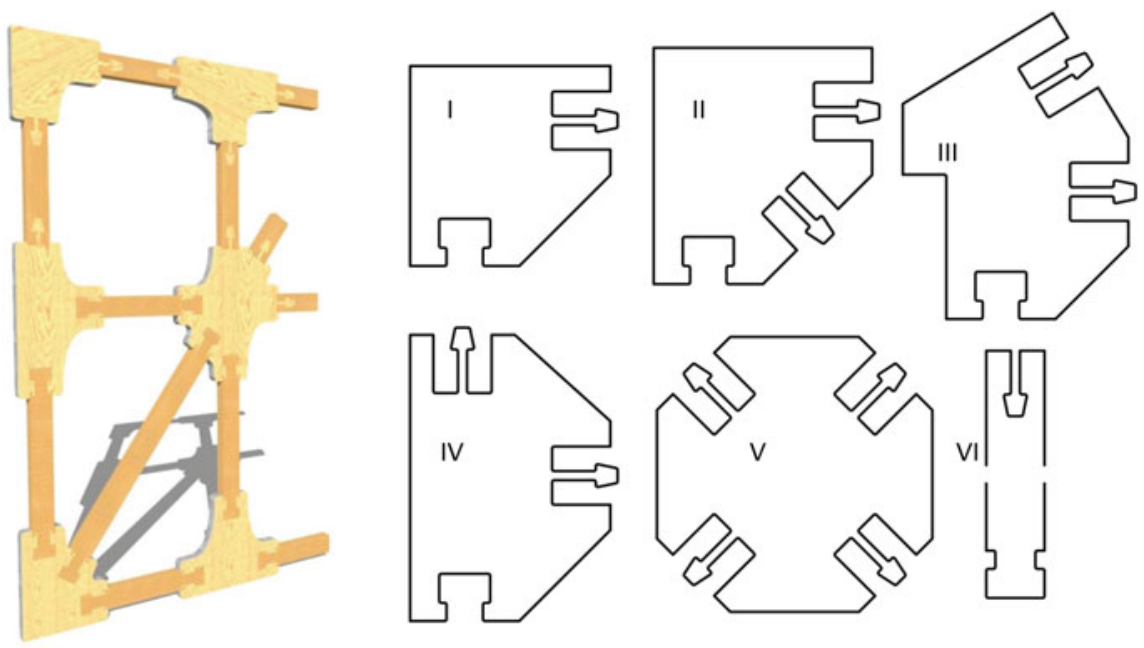

Fig. 13 The Makerjoint concept. (a) Sketch of a plane wall assembly, and (b) examples of nodes: I+II—corner nodes, III—roof node, IV—multiple floor node, V—bracing node, VI-Makerjoint beam (Rebstock et al. 2015)

\subsection{Environmental Aspects of EWPs}

Forestry and forest-related industries have never before been as focused as they are today in discussions regarding the major challenges of the future. Instead of utilizing the earth's limited resources, we have to use renewable materials, fossil fuels must be phased out and individual consumption must to a greater degree reflect the concerns for the climate and care for the environment. In this context, the emissions of carbon dioxide have been in focus for a long time. One way of reducing the emission of carbon dioxide is to use a greater proportion of timber products and to increase the life of these products so that the carbon is bound over a longer period of time. Another possibility is to replace energy-intensive materials with timber and timber-based products (Mahapatra and Gustavsson 2008). Timber and timber fibres have at least two or three utilization cycles before the material returns to the natural cycle. In the first cycle, the material is used in products such as timber, panelling, construction elements, furniture, etc. In the second cycle, the material can be used in a recycling process, i.e. as timber-based boards that are partly manufactured from recycled timber. Finally, in the third cycle, the timber material is used for energy conversion, e.g. in a power plant.

Kitek Kuzman and Kutnar (2014) have discussed the environmental impacts of primary wood products, and Werner and Richter (2007) reviewed the results of approximately 20 years of international research on the environmental impact of the life cycle of wood products used in the building sector compared to that of functionally equivalent products from other materials. Their study concluded that fossil 
fuel consumption, potential contributions to the greenhouse effect and quantities of solid waste tend to be much less for wood products than for competing products; impregnated wood products tend to be more critical than comparative products with respect to toxicological effects and/or photogenerated smog depending on the type of preservative; although composite wood products such as particleboard or fibreboard make use of a larger share of the wood of a tree than products made of solid wood, there is a high consumption of fossil energy associated with the production of fibres and particles/chips as well as in the production of adhesives, preservatives, etc.

Kutnar and Hill (2014) used a cradle-to-grave analysis to present the carbon footprint of 14 different primary wood products. The largest source of emissions for all sawn timber products is in removing the timber from the forest, while for kiln-dried sawn timber the drying process is a close second. For MDF and HDF, the extra energy required to convert the raw material to fibres, in addition to the energy required to apply pressure and heat to the products, is responsible for the bulk of the emissions from these products. The adhesives used in particleboard, plywood and OSB are responsible for the largest fraction of emissions from these products. This is especially significant considering the low total volume they represent in the final products. Glulam emissions derive mostly from the harvest and initial production of the softwood, but also from the extra energy required to apply pressure and set the adhesives used. Altering the system boundaries would yield different results. Furthermore, results would have been modified if the carbon footprint calculation took into account the carbon sequestration of wood, the use of recycled wood products and other similar issues pertinent to LCA. Furthermore, the results would have been different if a full life cycle of products, cradle-to-grave or cradle-to-cradle, had been considered.

There are many materials in the construction and housing industries that compete with timber, e.g. steel and concrete for frames and large constructions, bricks for walls and facades, and PVC and other plastics for windows, building features and furniture (Gustavsson et al. 2006). For timber as a material to be competitive against other materials, the timber's environmental advantages alone are not sufficient, i.e. that timber shows lower emissions of carbon dioxide according to calculations based on LCA criteria. Timber must also be competitive for its technical qualities, show a high material utilization during further processing, and not least, show a competitive economic yield during usage.

\section{Adhesives}

Bonding means connecting two solid bodies using an adhesive which fills the gap between the bodies and is able to transmit forces between the bodies. For wood, this means that the adhesive can penetrate beyond the surface and into cell lumens. An adhesive needs to be a liquid, or at least have sufficient flow under conditions of bonding so that it can come into good contact with the two surfaces to be bonded, 
and a good wetting and adhesion to the wood is always necessary. The adhesive must then solidify to hold the wood surfaces together, either by cooling and/or loss of water in the case of thermoplastics or by a chemical reaction to cross-link the material or increase the molecular weight in the case of thermoset adhesives. Chemical properties are important in bonding for developing adhesive and cohesive strength, while bond performance is measured as the mechanical strength for holding the wood surfaces together under various exposure conditions.

The art of gluing wood is very old. One of the earliest indications of the use of adhesive and veneer is found in Egyptian tombs and reliefs. Little is known of the methods used, e.g. how the wood was sawn into sheets or how the glue, which 3500 years later still holds thin layers of face wood to the heavier core, was prepared, but the work has endured and speaks for itself. Figure 14 shows a mural record found in Thebes that describes the production of an intarsia or plywood construction from about 1490-1436 B.C. Killen (2000) says that Egyptian carpenters began to laminate thin sheets of wood as early as the Third Dynasty (26862613 B.C.) in an attempt to fabricate a large sheet of wood which was dimensionally stable and equally strong in all directions. An example of six-ply wood, where the fibre orientation of one sheet is at right angles to the next, was discovered in a sarcophagus within the Third-Dynasty step pyramid complex of Djoser at Saqquara (Lauer 1933; Lucas 1936). There are also other examples of the early use of adhesives for the improvement of wood products. Insulander (1997) has studied the construction of the Scandinavian Saami two-wood bows. The oldest has been dated to ca. 200 B.C. but most of the finds are from the Middle Ages. This type of bow was constructed from two strips of wood, one of birch or other deciduous tree and one of compression wood from pine, which were glued together with an adhesive made from the skin from the perch fish (see also Schefferus 1673; Linné 1737). Protein-based adhesives were used until they were replaced by fossil-fuel-based systems beginning in the 1930s.

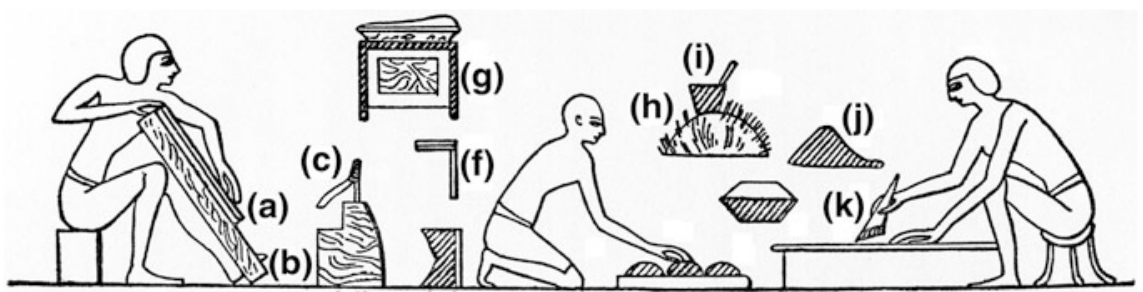

(d) (e)

Fig. 14 Mural record of veneering, discovered in the Sculpture of Thebes and dated as early as the time of the Thutmosis III (1490-1436 B.C.). The man to the left is applying veneer on a core of ordinary wood, the man in the middle is grinding something and the man to the right is applying adhesive with a brush. The mural record also shows (a) a piece of wood (b) applied to one of ordinary quality and (c) an adze fixed into (d) a block of wood. Some tools and equipment: (e) a ruler, (f) a right angle, (g) a box, (i) a adhesive pot on (h) the fire, (j) a piece of adhesive and (k) a brush, from Knight and Wulpi (1927) 


\subsection{Different Types of Adhesives}

Today, there are several wood-to-wood adhesives which produce joints stronger than the wood itself. Their use is, however, generally restricted to controlled wood-to-wood bonds that are well made, which require adequate, uniform pressure on smooth, clean, well-mated surfaces with even adhesive spread and factory conditions where temperature, adhesive age and formulation, press time, pressure and adequate wood moisture content can be carefully monitored.

It is difficult to determine with accuracy the use of adhesive in Europe. However, estimates suggest that the adhesive use for particleboard is split between UF ( $92 \%$ ), melamine UF (7\%) and isocyanates (1\%). UF is the primary adhesive used for MDF. OSB, on the other hand, is primarily made with polymeric diphenylmethane diisocyanates (75\%), while UF (10\%) and MUF (15\%) are also used (Kutnar and Burnard 2014).

Adhesives can be classified in many different ways. A division with respect to the chemical character and binding mode of the adhesive is probably the most useful. It is natural to begin with a breakdown between synthetic adhesives (see 3.2.1-3.2.9 below) and natural adhesives (see 3.2.10). The most common types of adhesives used in engineered wood are described below.

\subsubsection{UF-Urea-Formaldehyde Adhesives}

Urea-formaldehyde (UF) adhesives have several strong positive aspects: very low cost, non-flammable, very rapid cure rate and a light colour. UF adhesives are the largest class of amino resins, and are the predominate adhesives for interior products.

A major drawback of UF adhesives is their poor water resistance and they have high bond-line failure under accelerated ageing tests. Another area of concern is the long-term hydrolytic instability of these adhesive polymers, which generally show the least durability of any formaldehyde copolymer adhesive. UF adhesives are believed to depolymerize resulting in the continuing emission of formaldehyde. UF adhesives are typically used in the manufacture of products used in interior applications, primarily plywood, particleboard and MDF, because moisture exposure leads to a breakdown of the bond-forming reactions. Excessive heat exposure will also result in chemical breakdown of cured UF adhesives.

\subsubsection{PF-Phenol-Formaldehyde Adhesives}

PF polymers are the oldest class of synthetic adhesives, having been developed at the beginning of the twentieth century (Detlefsen 2002). These adhesives are widely used in both laminations and composites because of their outstanding durability, which derives from their good adhesion to wood, the high strength of the polymer 
and the excellent stability of the adhesive. PF adhesives are typically used in the manufacture of construction plywood and OSB where exposure to weather during construction is a concern. The PF adhesives can serve in almost all wood-bonding applications, as long as the adhesive in the assembly can be heated. In many cases, if moisture resistance is not needed, a lower cost UF adhesive can be used. Like most adhesives, the commercial products contain more than just the resin, depending on the application. The most common additive is urea to provide improved flow properties, to scavenge free formaldehyde and to reduce the cost.

\subsubsection{MF-Melamine-Formaldehyde Adhesives}

Like formaldehyde adhesives made with phenol and resorcinol, MF adhesives have a high water resistance, but they are much lighter in colour than the others. MF adhesives are most commonly used for exterior and semi-exterior plywood and particleboard, for finger-joints, for decorative laminates, paper treating and paper coating. MF resins are often used in combination with UF.

The limitation of the MF adhesives is their high cost due to the cost of the melamine. This has led to the use of MUF adhesives that have much of the water resistance of MF adhesives, but at a substantially lower cost. The MUF adhesives, depending on the melamine-to-urea ratio, can be considered as a less expensive MF that has lower durability or as a more expensive UF that has better water resistance (Dunky 2003). The MUF adhesives can replace other adhesives that are used for some exterior applications.

\subsubsection{MDI-Methylene-Diphenyl-Diisocyanate Adhesives}

Several classes of adhesives used in wood bonding involve the use of isocyanates, because of their reactivity with groups that contain reactive hydrogens, such as amine and alcohol groups, at room temperature. This allows great flexibility in the types of products produced, because they can self-polymerize or react with many other monomers. Isocyanates are most often used to produce PU by reacting with liquid diols.

Polymeric diphenylmethane diisocyanates (pMDI) are commonly used in wood bonding and are a mixture of the monomeric diphenylmethane diisocyanate and methylene-bridged polyaromatic polyisocyanates. The higher cost of the adhesive is offset by its fast reaction rate, its efficiency of use and its ability to adhere to difficult-to-bond surfaces. pMDI adhesives are used as an alternative to PF adhesives, primarily in composite products fabricated from strands, and they are sometimes used in core layers of strand-based composites, with a slower curing PF adhesive in the surface layers. The use of pMDI requires special precautionary protective measures because the uncured adhesive can result in chemical sensitization of persons exposed to it. A cured pMDI adhesive poses no recognized health concerns. 


\subsubsection{PU-Polyurethane Adhesives}

PU are made up of long polyol chains that are tied together by shorter hard segments formed by diisocyanate and in some cases chain extenders (Pizzi and Mittal 2003). The polyol chains impart low-temperature flexibility and room-temperature elastomeric properties. The advantage of PU adhesive is the reaction of isocyanates with the active hydrogen on the surface, subsurface or air making possible the gluing of surfaces with different moisture contents. The curing time is relatively short, 3-4 h, resulting in a strong, water-durable bond. The disadvantages of the PU adhesives are isocyanate emissions and the higher pressure needed when clamping.

\subsubsection{Epoxy Adhesives}

Epoxy adhesives are two-component thermoset polymers based on an epoxy, epoxide or ethoxyline group resin and a hardener (Wallenberger and Bingham 2010). The advantages of epoxy adhesives are their good chemical and thermal resistance and low clamping pressure. The curing agent, the hardener, produces an insoluble, intractable, cross-linked thermoset polymer. The properties of the cured epoxy adhesive depend on the type of hardener and on the cure temperature.

Epoxy adhesives are currently mostly used for the fibreglass reinforcement of, e.g. wooden boats and glulam. Their advantages are stronger bonds with the wood, a high durability and a greater impact resistance than e.g. polyester adhesives, and they are relatively easy to work with. As disadvantages, epoxy adhesives are rather expensive, have long curing cycles. Also, most of the epoxy suffers from "amine blush", i.e. after application and during the curing process the epoxy releases a blush to the surface.

\subsubsection{PVAc-Polyvinyl-Acetate Adhesive}

Vinyl acetate homopolymers are simply made adhesive bases manufactured by addition polymerization in the presence of water and stabilizers (Pizzi and Mital 2003). External plasticizers, e.g. dibutyl phthalate are usually added to confer flexibility and to lower the temperature at which they form a film on drying (Pizzi and Mittal 2003). Higher quality products may be made by the copolymerization of ethylene with vinyl acetate to form ethyl vinyl acetate (EVA). The advantages of PVAc adhesives are their low costs, ease of use and minimum of harmful environmental effects. The disadvantages of PVAc adhesives are their low water durability. This drawback can be reduced by blending the PVAc with MUF resins. 


\subsubsection{Resorcinol Adhesives}

Cold-setting adhesives with good water resistance are the resorcinol adhesives. Resorcinol-formaldehyde (RF) and phenol-resorcinol-formaldehyde (PRF) adhesives are mainly used in the manufacture of structural exterior grade joints. Among their net advantages of strong joints when setting at ambient temperatures, RF and PRF adhesive are rather unavailable and are thus expensive.

\subsubsection{Polyester Adhesives}

Unsaturated polyester resins consist of low molecular weight condensation products of unsaturated and saturated biacids and diols dissolved in a styrene monomer or other suitable reactive diluents (Wallenberger and Bingham 2010). The unsaturation of the adhesive systems provides vinyl sites for cross-linking and the creation of the thermoset adhesive. Cross-linking can be initiated by various activators at ambient or raised temperatures. Organic peroxides are used as initiators and cobalt complexes are used as accelerators, to reduce the minimum temperature at which the decomposition of the organic peroxide takes place. Polyesters are mainly used for the fibreglass reinforcement. The advantages of polyester adhesives are their wide choice, reduced costs and curing at room temperature. As disadvantages can be mentioned styrene emission and the rather low impact strength of the surface.

\subsubsection{Bio-Based Adhesives}

Bio-based adhesives were widely used prior to the early 1970s in construction plywood. In the mid-1970s, they were supplanted by PF adhesives, because of the superior bond durability provided by phenolics. The most common bio-based adhesives are protein-based, e.g. from animal bones and hides, milk (casein), blood, fish skins and soybeans. Natural protein adhesives are not useful at high moisture levels. Adhesives from renewable resources are, however, still of interest, not least for environmental reasons, but none had the performance and production cost to make an impact in the wood adhesive market until soy flour adhesives, using a polyamidoamine-epichlorohydrin (PAE) resin, were developed by Li et al. (2004). Other adhesive systems have been developed using soy proteins in combination with other adhesives. When soy flour becomes a part of the adhesive network rather than just being used as a filler, it can replace about half the phenol in basic or neutral formulations that meet the performance requirements for the face adhesives of, e.g. OSB (Frihart 2011). It is also possible to obtain bio-based adhesives from wood itself, e.g. tannin and lignin.

Tannins are used as a partial replacement of phenols because of their good reactivity, but the volumes are small because of their limited availability (Pizzi 2006). Tannins are more reactive than phenol but more expensive. Limitations of tannin-based adhesives, compared to synthetic adhesives, are their high viscosity, 
limited availability and inconsistent source and therefore reactivity. Tannin has been used as an adhesive in particleboard and MDF production, and for laminate and finger-joint bonding.

Lignin is available in large quantities at low cost, as a by-product of pulping processes for papermaking. Lignin is not as reactive as tannin with formaldehyde but it can be modified. Lignosulfonates from the sulfite pulping of wood have been found to be more useful for the production of reactive lignins (Rowell 2005). Lignin continues to be evaluated as a partial replacement of phenols, but the volume used in wood adhesives has been low because of its limited reactivity. New biorefinery technology may provide more reactive lignins in the future, and the amount of lignin that is available at a competitive price is substantial.

\subsection{Environmental Aspects of Adhesives}

Although wood is a natural material, bonded wood products have caused some environmental concern related to formaldehyde and other volatile compounds in the adhesive formulations used in bonded wood products. Heating increases the problem, as it raises the vapour pressure of reactive chemicals. Isocyanates can react rapidly with compounds in the human body. Both EPI and PU adhesives contain isocyanates. The preparation and processing of epoxy also poses significant health risks in the form of, e.g. allergies. There are also legal requirements which aim to depress the levels of emission especially of free formaldehyde.

Environmental interest and the rising cost of petroleum-based adhesives, i.e. synthetic adhesive, has made bio-based adhesive increasingly interesting. A recent example is that using polyamidoamine-epichlorohydrin (PAE) resin as a co-reactant has been found to be effective in increasing the wet bond strength of soy adhesives and has led to a resurgence in soy-based adhesive consumption (Frihart and Birkeland 2014).

The foremost area of environmental concern with regard to adhesives has been formaldehyde emissions from bonded products, mainly those using UF adhesives. Products bonded with UF-based adhesives such as plywood, MDF and particleboards are often used, e.g. in kitchen joinery and furniture and they may therefore lead to an increase in the level of formaldehyde in the indoor air. Formaldehyde can also be cleaved from acid-curing inks and varnishes. Formaldehyde can react with biological systems in reactions similar to those that are used for the curing of adhesives. The problem can arise from both unreacted and generated formaldehyde (Rowell 2005). Unreacted formaldehyde is a problem during the manufacturing operation and in freshly produced composites, but formaldehyde emissions from composites decrease with time after production. Formaldehyde can also be generated by the decomposition of some formaldehyde copolymer adhesives, in particular the UF adhesives. These adhesive bonds are more prone to hydrolysis, generating free formaldehyde. 
Fig. 15 Change in content of cleavable formaldehyde from particleboards in Europe during 1970-1990, measured as perforator value, expressed as $\mathrm{mg}$ formaldehyde per $100 \mathrm{~g}$ dry material. The perforator method is described in the European standard EN-120 (CEN 1992)

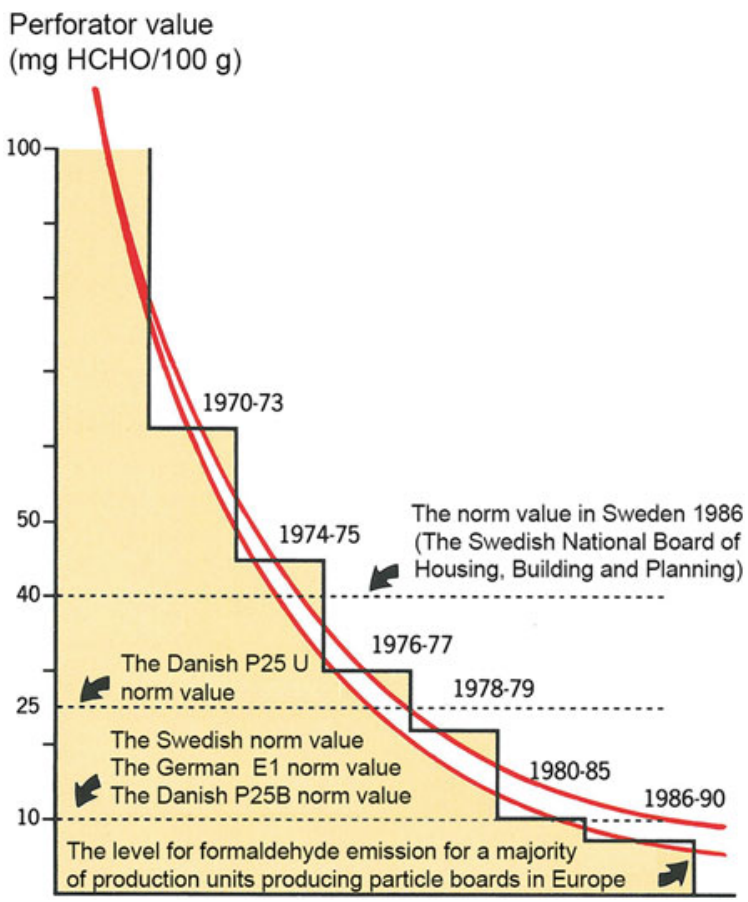

The greatest concern about formaldehyde is with particleboard, due to the large volume of indoor usage and the large amount of adhesive in the product. The particleboard industry has therefore together with adhesive manufacturers over a long period focused on reducing formaldehyde emission from the boards. Figure 15 shows the reduction in formaldehyde emission from particleboards in Europe from 1970 to 1990.

Richter (2001) provides a comparison of environmental assessment data of different wood adhesives. Little LCA data have been published so far for resins based on renewable resources or components (e.g. tannins, lignins, proteins). A study of the use of a lignin-based phenolic adhesive in combination with a laccase-initiating system has found a significant environmental impact associated with enzyme production (González-García et al. 2011).

\section{Wood Modification}

Strictly, wood modification involves a change in the macromolecular chemical composition of the wood cell wall, i.e. chemical or thermal modification. In this section "impregnation modification" where the cell wall is filled with an occluding substance is also included. Wood modification involves the action of a chemical, 
biological or physical agent upon the material, resulting in the desired property enhancement during the service life of the modified wood. The properties of wood are the result of the chemistry of its cell-wall components and the matrix they are in. If the chemistry is changed at the molecular level, the properties change and performance also changes. With the demands of society today, the modified wood should itself be non-toxic under service conditions and furthermore, there should be no release of any toxic substances during its life time, or at the end of its life following disposal or recycling. If the modification is intended for improved resistance to biological attack, then the mode of action should be non-biocidal. Historically, that has not been the case.

The market, especially in Europe, for new durable products of modified wood has increased substantially during the last few years. This increased interest depends partly on the restricted use of toxic preservatives due to an increased environmental concern. Another motive is the need for reduced maintenance. Three wood modification concepts, which have recently been commercialized, are acetylation, furfurylation and thermal treatment.

\subsection{Preservation of Wood Against Biological Attack}

Wood impregnation is in general a chemical treatment providing protection against various kinds of injurious organisms which decompose the wood in its use environment. The impregnation is carried out in industrial plants and is in many cases linked to the production line of the sawmill. Wood protection plants can historically be divided into impregnation plants, where the wood is treated to resist rot, and dipping plants, where the wood is treated to provide protection against mould and blue-stain fungi. The purpose of impregnation is to ensure that the wood, when it is used, shall have a longer life and resist attack from destructive organisms.

Dipping, on the other hand, does not give a product which is more resistant in use. It only prevents the wood from the blue-stain damage which can arise if the wood has too high a moisture content under unfavourable conditions, e.g. during storage before drying or in timber-yard drying. Dipping is not really an impregnation method, but from the 1940s it was frequently used in sawmills as a short-term protection against blue-stain fungus. Dipping has also been carried out at a few independent wood impregnation plants. The first dipping chemicals used were water-soluble fluoride-based agents. Later, phenolic agents (pentachlorphenol) came to completely dominate the dipping of sawn wood at the sawmills, but the need for dipping decreased when more and more sawmills started to instal kilns for wood drying instead of drying the wood outdoors, and in the 1970s the use of the toxic pentachlorphenol was forbidden as a dipping agent and the method is very seldom used today.

It is chiefly wood species with a low biological resistance which are impregnated, e.g. Scots pine, because the sapwood in pine, which has a low resistance in outdoor use, has open pores between the cells even after the wood has been dried, 
and this means that the impregnation liquid easily penetrates into the sapwood. Beech and spruce are also impregnated but not to the same extent as pine wood.

The birth of the wood impregnation industry dates back to the end of the 1850s. At first, only telegraph poles and railway sleepers were impregnated, and a copper sulphate solution (copper vitriol) was then used. When the first railways were built, it was realized that the sleepers must be protected against rot, and attempts were therefore made to impregnate sleepers with, e.g. copper sulphate solution according to the Boucherie method. Impregnation with creosote soon also became a relatively common impregnation method.

The Boliden mining company in Sweden, which started its activities in the 1920s, obtained large amounts of arsenic in the processing of iron ore, and in order to find a market for this by-product, research in the sphere of wood protection was initiated in 1932. Towards the end of the 1930s, sufficient knowledge had been obtained to make it possible to exploit the Boliden impregnation method to a greater extent. At this stage, the engineer Bror Häger was the R\&D manager, and the Boliden impregnation salt developed by Häger contained arsenic, chromium and zinc. This agent was at first used in so-called open-tank plants. Pressure impregnation had thus come to stay. This meant considerable large-scale operation advantages compared with the Boucherie and open-tank methods and made possible an increase in the use of impregnated sawn wood, a product which in the 1940s became increasingly important. The development of new salt agents was also intensive during and just after the Second World War. Two products which came to have a great commercial importance and dominated the wood protection market in the north of Europe for more than two decades were Boliden K33 and KP Cuprinol.

The volume of impregnated sawn wood has increased greatly during the last few decades and today it exceeds the volume of impregnated sleepers and telegraph poles. There are several reasons for this: new spheres of application for impregnated wood were introduced (garden furniture, patios, playgrounds, etc.), the building of houses increased rapidly at the end of the 1960s and in the early 1970s, and there was a generally increased awareness of the advantages of using impregnated wood for certain purposes.

In the 1970s, impregnation of window frames with an oil-soluble protective agent according to the so-called double vacuum method was common. This type of impregnation has since then become increasingly widespread in the window joinery industry. Today, the wood impregnation activity at many sawmills is an important feature of their advanced refining activity. Substantial volumes of sawn wood, often of low quality, are impregnated in the spring for sale in the summer half of the year via building material retailers.

Most of the wood protection agents used are now classed as biocides and they are in many cases very toxic. The following impregnation methods have been used or are still being used today:

The French physician and chemist Auguste Boucherie (1801-1871) invented the Boucherie method for preserving wood by drenching it with mineral substances, usually copper vitriol, and this method was called "to boucherize" after him. In the Boucherie method, unbarked logs are injected with a protective agent 
(copper sulphate solution) through tubes at the root end. Since the tank is placed 10-12 metres higher than the logs, the protective agent is pressed into the log. After 5-15 days, the impregnation is seen to be complete when liquid begins to drip from the top end and via knots. The next stage is to debark the logs.

Open-tank impregnation is used principally for the impregnation of telegraph poles. The wood is submerged in a tub with an airtight lid. Steam is led into the tub and after $8-12 \mathrm{~h}$, the wood is heated. After this heating, a cold impregnation solution is fed into the tub and the cooling leads to an underpressure, as a result of which the solution is sucked into the wood. This part of the process takes 30-35 h. The Boliden impregnation salt is usually used in this method.

There are a large number of pressure impregnation methods. The common processes are the Fullcell/Bethell method (ca. 6001 impregnation liquid $/ \mathrm{m}^{3}$ sapwood), the Rüping method (ca. $200 \mathrm{l} / \mathrm{m}^{3}$ ) and the Lowry method (ca. $300 \mathrm{l} / \mathrm{m}^{3}$ ). In the latter two impregnation methods, the uptake of impregnation liquid is less but, at the same time, the concentration of the active components is higher. The different methods give different penetration depths, which means that the products from the different methods have different spheres of application. In pressure impregnation, the main agents used are creosote and water-soluble metal-based agents.

The Fullcell method started to be developed in the middle of the nineteenth century and was based on impregnation with creosote, but since the 1940s chromium-based salts have been used. This is still the dominant process for salt impregnation. The process involves: the pre-vacuum stage $(30 \mathrm{~min})$ to removes air from the cell cavities in order to increase the liquid absorption, and the filling of impregnation liquid while maintaining the vacuum; the pressure stage $(0.5-1 \mathrm{~h})$ when the pressure is retained until no more impregnation liquid is absorbed, after which the liquid is evacuated; the post-vacuum stage $(15-30 \mathrm{~min})$ to make the surface of the wood dry for easier handling; the draining and drying stage to the desired moisture content.

The Lowry method was developed at the beginning of the twentieth century and was used chiefly on a small scale for chlorophenol-based agents in the 1960s and 1970s. The various stages of this process are: filling with impregnation liquid under atmospheric pressure, the pressure period and the vacuum period. During the post-vacuum period, excess liquid is pressed out and this makes the wood surface dry. For this reason, the concentration of impregnation liquid is twice as high.

The Rüping method was also developed at the beginning of the twentieth century. The impregnation agent used is creosote which must be heated to $100-120^{\circ} \mathrm{C}$ before it is used.

Vacuum impregnation is used primarily for joinery materials for use above ground. Until the 1990s, substances having organic tin compounds as the active component were used, the different stages of the process being: the pre-vacuum stage to empty the wood cells of air; the filling of impregnation liquid while the vacuum is maintained; the atmospheric pressure stage when the cells are filled with impregnation liquid, the pressure stage to ensure that the impregnation liquid is spread as uniformly as possibly in the material; and the post-vacuum stage to ensure that the timber surface is dry. 
Vacuum impregnation according to the Royal method was put into operation in 1970, primarily for slender materials such as panels and window timber. The process takes about four hours and is carried out in two stages at a temperature of about $85{ }^{\circ} \mathrm{C}$; first a pressure impregnation with an ammoniacal copper agent and thereafter a vacuum period when the timber is treated with a special oil to reduce the uptake of moisture by the wood, sometimes with the addition of a coloured pigment.

Impregnating agents that are used or have been used can be divided as follows:

- Creosote (pressure impregnation),

- Water-soluble metal-based agents such as chromium-based salts and ammoniacal copper (pressure impregnation),

- Solvent-based agents (pressure impregnation),

- Solvent-based and water-soluble agents such as organic tin compounds (vacuum impregnation).

Impregnated wood is used in the same way as untreated wood and therefore bonding is also necessary after impregnation. Treated wood may be glued with synthetic adhesives of the phenol or resorcinol type, but the surface should be cleaned with steam, or wiped off in the case of oily preservatives. Gluing of treated wood requires a higher temperature and pressure. Wood treated with salt-type, waterborne preservatives is more difficult to glue and a higher temperature and higher pressure are needed.

\subsection{Preservation of Wood Against Fire}

Wood is a combustible material and this can sometimes limit its use. The wood's flammability can be influenced chemically with fire and flame retardants. Fire retardants provide protection against a fully developed fire and can affect the charring rate, ignitability, flame speed, smoke development and mechanical properties. Flame retardants are used for protection against the initial fire. The additives used in both cases are the same, i.e. mainly inorganic salts. Because fire-retardant treatment reduces the flammability of the wood product, fire-retardant treated wood products are often used for interior joinery in rooms, auditoriums, etc., where codes require materials with low surface flammability.

Fire retardant treatment of wood products, e.g. by chemical modification, may considerably improve their reaction to fire, and the highest fire classification for combustible products may be reached (Euroclass B). This allows a wider use of visible wood, both as interior wall and ceiling linings and as exterior cladding. Common problems of fire-retardant treatments are the risk of migration of the fire-retardant chemicals within the wood product and salt crystallization on the surface due to a high moisture content, and the loss of fire-retardant chemicals by leaching or other mechanisms. Both problems lead to a poorer fire performance, and also a risk of a change in the service life of the products. Some fire-retardant 
chemicals may cause corrosion on metals and affect the properties of the wood such as paintability, colour and mechanical strength. The toxicity of the fire retardants is an important factor that must also be considered.

The fire-retardant treatment may take place either by vacuum impregnation, by incorporation during the manufacturing of wood the products, or by surface treatment of the final product. In all cases, the amount of fire-retardant chemicals in the final product is decisive for its reaction to a fire. Normally $15-20 \%$ of flame retardant based on the wood weight is added by impregnation, but large variations occur.

In vacuum impregnation, inorganic salts are the most commonly used fire retardants for interior wood products. These salts include ammonium sulphate, boric acid, diammonium, guanylurea and monoammonium phosphate, sodium tetraborate and zinc chloride.

There are a large number of commercial flame-retardant surface coatings on the market and it is not possible to describe them in detail. The coatings are divided into intumescent and non-intumescent. The most effective flame-retardant surface coatings are intumescent coating, as in a fire they develop insulating foam on the surface of the wood. Intumescent formulations include a dehydrating agent, a char former and a blowing agent. Potential dehydrating agents include polyammonium phosphate. Ingredients for the char former include starch, glucose and dipentaerythritol. Potential blowing agents include urea, melamine and chlorinated paraffins. $300-500 \mathrm{~g} / \mathrm{m}^{2}$ of paint is a common amount to give a good effect of a flame-retardant surface coating. Non-intumescent coatings include formulations of water-soluble salts such as borax, ammonium and diammonium phosphate.

\subsection{Acetylated Wood}

The idea of acetylation dates back to 1928 (Fuch 1928; Horn 1928; Suida and Titsh 1928) and later on pioneering work was performed by Stamm and Tarkow in the 1940s (Tarkow et al. 1946). Acetylation of wood is a so-called single-site reaction where one acetyl group replaces the hydrogen atom in one hydroxyl group in the wood cell wall and increases the naturally occurring acetyl content of wood from 1-3 to $20 \%$ (Rowell et al. 1986). The acetylation process involves impregnation of the wood with acetic anhydride which is then reacted at elevated temperature, which results in esterification of the accessible hydroxyl groups in the cell wall with the formation as a by-product of acetic acid, Fig. 16. The resulting modified wood material has a lower equilibrium moisture content (EMC), a greater dimensional stability, maintained strength (but exhibits a brash failure mode), good weathering resistance under clear coatings, and superior resistance to biological degradation. The acetic acid must be removed from the wood material, otherwise the product will smell of acetic acid. 


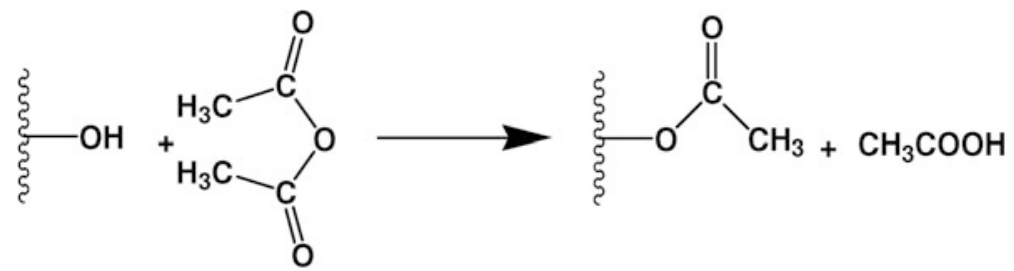

Fig. 16 The reaction of acetic anhydride with hydroxyl groups $(-\mathrm{OH})$ in the cell wall in wood resulting in acetic acid as a by-product $\left(\mathrm{CH}_{3} \mathrm{COOH}\right)$

\subsection{Furfurylated Wood}

The wood furfurylation process involves pressure impregnation of wood with furfuryl alcohol, which is polymerized and reacted within the cell wall at elevated temperatures. The resulting material has a high dimensional stability, improved mechanical behaviour, except for impact resistance, and improved resistance to fungal decay. The research concerning furfurylation was also pioneered by Stamm and co-workers in the early 1950s (Goldstein 1955) and the commercial wood furfurylation process and characterization of the properties is described by Lande et al. (2004).

\subsection{Thermal Modification}

In recent decades, developments in the area of thermal treatment have accelerated considerably. During the 1980s, French and Japanese industries began to modify wood with the help of heat to increase the resistance to microbial attack. Since then, interest in thermal treatment has increased and several thermal treatment processes for sawn timber have been developed and industrialized in Europe.

Thermally modified timber (TMT) is, according to CEN (2007), wood in which the composition of the cell wall material and its physical properties have been modified by exposure to a temperature higher than $160{ }^{\circ} \mathrm{C}$ under conditions of low oxygen availability. The wood is altered in such a way that at least some of the wood properties are permanently affected. This product is related to heat-treated wood, but to distinguish it from heat sterilization at lower temperature $\left(\approx 55^{\circ} \mathrm{C}\right)$ with the purpose of killing pests in solid wood materials and preventing their transfer between continents and regions, we use the terms thermal treatment/ processing and TMT. Thermal treatment significantly influences the properties of wood, e.g. hygroscopicity and dimensional stability, resistance against fungi and insects, mechanical properties, and also properties such as colour, odour, gluability and coating performance, Table 3 .

In the beginning of the twentieth century, the use of heat and moisture in wood processing came into focus. It had been observed that wood dried at a high temperature changes colour, has a greater dimensional stability and has a lower 
Table 3 Main differences in properties of thermal-modified timber (TMT) compared with untreated wood

\begin{tabular}{l|l}
\hline $\begin{array}{l}\text { Desirable property } \\
\text { changes }\end{array}$ & Undesirable property changes \\
\hline $\begin{array}{l}\text { Lower equilibrium } \\
\text { moisture content }\end{array}$ & $\begin{array}{l}\text { Lower modulus of rupture (MOR) and to some extent lower } \\
\text { modulus of elasticity (MOE) }\end{array}$ \\
\hline $\begin{array}{l}\text { Greater dimensional } \\
\text { stability }\end{array}$ & Lower impact strength \\
\hline $\begin{array}{l}\text { Greater durability against } \\
\text { decay }\end{array}$ & Greater brittleness (complicates e.g. machining) \\
\hline $\begin{array}{l}\text { Lower thermal } \\
\text { conductivity }\end{array}$ & Lower hardness (Brinell hardness) \\
\hline Lower density & \\
\hline Dark brown colour & \\
\hline Characteristic smell \\
\hline Longer pressing time for gluing
\end{tabular}

hygroscopicity (Tiemann 1915; Koehler and Pillow 1925). After the First World War, comprehensive studies were made on the effect of the kiln drying temperature on the strength of wood for the aviation industry in the United States (Wilsson 1920). Stamm et al. (1946) reported the first systematic studies on wood thermal treatment, illustrating an increase in dimensional stability and an increase in the decay resistance of wood treated at a temperature between 120 and $320{ }^{\circ} \mathrm{C}$, but their results were not really industrialized until the mid-1990s when several thermal treatment processes were commercialized.

Most industrialized thermal treatment processes today involve temperatures between 150 and $260{ }^{\circ} \mathrm{C}$ for times of several hours. The thermal treatment of wood above $300{ }^{\circ} \mathrm{C}$ is of limited practical value due to the severe degradation of the wood material (Navi and Sandberg 2012). The goal when treating wood is to increase its dimensional stability and resistance to biological degradation. The thermal treatment process is in most cases performed in vacuum, in air or in an inert gas such as nitrogen. Preheated oil can also be used, in which case the oil acts as a heat transfer medium and also excludes oxygen from the wood.

During thermal treatment, the chemical structure of the wood is transformed by autocatalytic reactions of the cell wall constituents. It is known that during the thermal treatment of wood under moist conditions, carbonic acids, mainly acetic acid, are initially formed as a result of cleavage of the acetyl groups particularly of hemicelluloses (Dietrichs et al. 1978; Bourgois and Guyonnet 1988). Depending on the acid concentration and on the temperature, hemicelluloses are hydrolysed into oligomeric and monomeric structures (Klauditz and Stegmann 1955; Carrasco and Roy 1992). The weight loss from hardwoods is greater than that from softwoods, probably due to the greater content of acetyl groups in hardwoods (Hillis 1975). Subsequently, the monomeric sugar units are dehydrated to aldehydes, furfural being formed from pentoses and hydroxymethylfurfural from the dehydration of hexose sugar units (Ellis and Paszner 1994). 
The only type of thermal treatment process that adds a substantial proportion of external substances to the wood material during processing is that which using oil as process medium. The oil can be a plant oil such as rapeseed oil, sunflower oil, soybean oil. Tall oil or black liquor derivatives, in addition to drying oils such as linseed oil are also conceivable. Linseed oil proved to be unproblematic, although the smell that develops during the thermal treatment may be a drawback.

Thermal-treated woods are characterized by considerable changes in their chemical properties, resulting in a significant odour (Kamdem et al. 2000). The degradation products of a range of wood components cause this typical odour (Boonstra et al. 2006). The formation of toxic polyaromatic compounds during thermal treatment has been discussed in the literature. It has been suggested that the formation of these products leads to increased resistance fungal decomposition and micro-organisms (Kamdem et al. 2000). Increasing indoor applications of thermal-treated wood have led to an interest in elucidating the chemical composition of these emissions and in developing ways to reduce them.

Thermal treatment of wood is an innovative process currently being implemented in industrial applications. Although many technical aspects of thermal treatment are well known, the fundamental influence of the process on product performance, the environment and end-of-life scenarios remains unknown.

\section{Surface Treatment}

A coating is a covering that is applied to the surface of an object, usually referred to as the substrate. Paints and lacquers or varnishes are coatings that usual have dual purposes; to protect the substrate and to be decorative. In the case of wood, the coating is both decorative and functional. The surface should have an attractive colour or exaggerate the natural appearance of the wood, and at the same time protect the surface or the function of the wood product.

The largest segment of the paint industry produces architectural coatings, including consumer paints, which make up approximately half of the total quantity of coatings produced annually in the world. These products are used to beautify and maintain the surfaces in different places in society. Coatings applied at the time of manufacture of a product are known as industrial coatings, and they represent about $50 \%$ of all the coatings used worldwide.

\subsection{The Components of a Coating}

The function and properties of a coating depend on how well the substrate, in our case wood, interacts with the coating. The properties of a coating are strongly influenced by its main components which are: 
- Binders

- Pigments

- Solvents

- Fillers

- Additives

The binder binds the pigment particles to each other and to the wood as a protective layer, and it features a range of properties such as wetting, film formation and penetration that can be altered and controlled. Organic binders can be described as drying adhesives. Today, most organic binders are synthesized from crude oil, but there are still conventional binders based on oils from plants such as linseed oil. Typical binders include nitrocellulose, alkyd resins, amino resins, acrylates and polyester resins.

Pigments give colour and contribute to making the surface layer opaque. The pigment grains are usually so small that they cannot be distinguished by the naked eye and can also contribute to other properties of the coating such as diffusivity and gloss. Both soluble and dispersed pigments are used for stains.

With added solvents, the coating has a viscosity so that it can be applied to the wood. The solvent may also affect the penetration of the coating into the wood. Common solvents are water, white spirit, alcohols and turpentine. Earlier, xylene was a common solvent, but because of its high toxicity it is no longer used.

Fillers are used to modify the colour strength, the gloss of the coating and the extent to which the coating covers the substrate. Coating manufacturers also use fillers to reduce the manufacturing cost for the coatings.

Additives in coatings may include fungicides, alcohols or glycerol, to prevent mould growth, make the colour drip-free, accelerate the drying or improve adhesion, and to regulate certain properties of the finish such as gloss, consistency, wetting, flow, blister prevention and sandability. Specifically, polymeric coatings need a high amount of additives that provide desirable features such as wettability, preservative properties and cushioning foaming.

Coatings are available in a very wide variety depending on the properties, use, price, etc., and can be roughly divided into water-soluble and water-free coatings, Fig. 17. The water-soluble coatings can in turn be subdivided into two groups according to how the binder, pigment and solvent interact: slurries and dispersions. In a slurry the binder and the pigment are suspended in the solvent. If the coating is left, the pigment settles to the bottom and stirring is necessary before each new application. This separation does not occur in a dispersion, in which the pigments are so small that they remain suspended and the coating constitutes a suspension. In emulsion coatings, comminuted oil is dissolved in water with the help of an emulsifier. All water-soluble paints dry by evaporation of the water.

Another type of division is into organic and inorganic coatings, referred to as pigments. Organic colours are based on carbon compounds. Typical water-soluble organic coatings are those containing organic pigments, the inorganic pigments usually being classified as white, black and coloured pigments, Table 4 . 


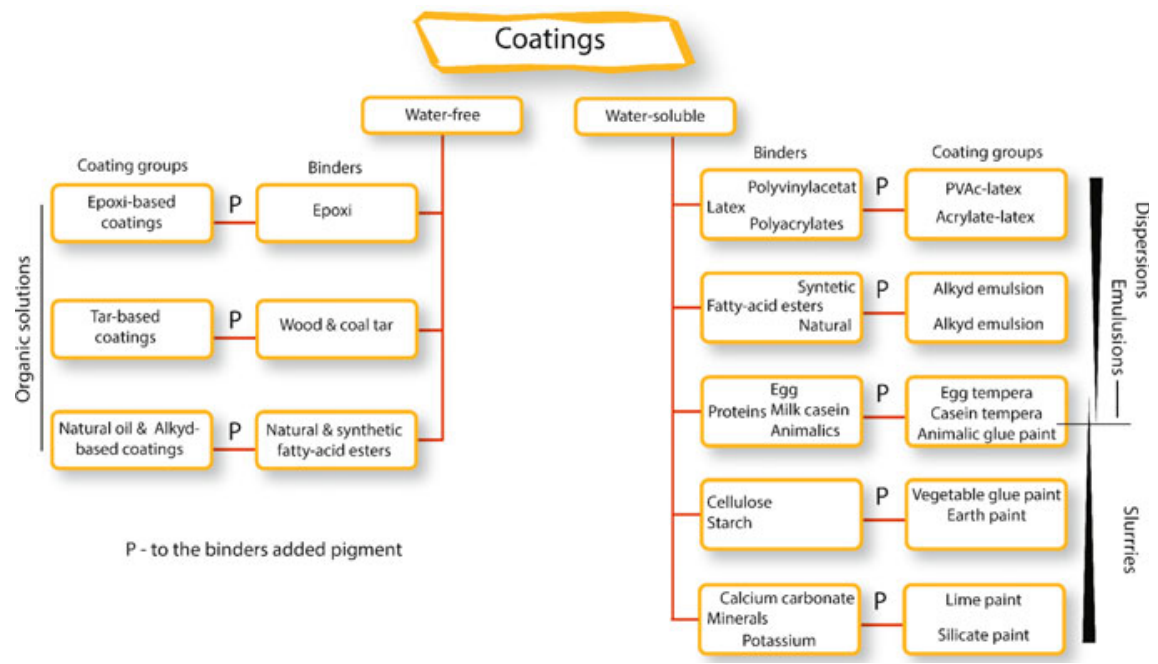

Fig. 17 Classification of water-free and water-soluble coatings based on binders

Table 4 Examples of organic and inorganic pigments commonly used in coatings

\begin{tabular}{l|l|l|l|l}
\hline \multirow{2}{*}{ Organic pigment } & \multicolumn{4}{l}{ Inorganic pigment } \\
\cline { 2 - 5 } & White & Black & Coloured \\
\hline $\begin{array}{l}\text { Aniline }(\text { Phenylamine, } \\
\left.\mathrm{C}_{6} \mathrm{H}_{5} \mathrm{NH}_{2}\right)\end{array}$ & $\begin{array}{l}\text { Titanium } \\
\text { white }\end{array}$ & $\begin{array}{l}\text { Carbon } \\
\text { black }\end{array}$ & $\begin{array}{l}\text { Earth pigments (ochres, } \\
\text { umbras, Terra di siena...) }\end{array}$ & Green earth \\
\hline $\begin{array}{l}\text { Azo compound } \\
\left.\mathrm{R}-\mathrm{N}=\mathrm{N}-\mathrm{R}^{\prime}\right)\end{array}$ & $\begin{array}{l}\text { Zinc } \\
\text { white }\end{array}$ & $\begin{array}{l}\text { Ferric } \\
\text { black }\end{array}$ & Ferric yellow & Cobalt green \\
\hline Phthalocyanine & Chalk & $\begin{array}{l}\text { Bone } \\
\text { black }\end{array}$ & English red Swedish red & $\begin{array}{l}\text { Silica and } \\
\text { silicates }\end{array}$ \\
\hline Petroleum & Dolomite & Coal & Red lead & Ferrycyanide \\
\hline Coal & & $\begin{array}{l}\text { Ferric } \\
\text { oxide }\end{array}$ & $\begin{array}{l}\text { Ultramarine } \\
\text { Prussian blue }\end{array}$ & $\begin{array}{l}\text { Chrome } \\
\text { oxide }\end{array}$ \\
\hline
\end{tabular}

Depending on the binders they contain, lacquers, paints and fillers pass through different phases during the curing and drying process, and may therefore be classified as water-soluble coatings, air-drying coatings and reaction-curing coatings.

\subsection{Water-Soluble Coatings}

Water-based coatings are mainly thermoplastic systems, acrylate dispersions being the most common. These can be one-component, two-component or UV-curing systems, and in terms of quality they have improved significantly. There is now a 
water-soluble alternative for every application area and these products cure faster than the more conventional coating systems. Environmental legislation concerning reduced solvent emissions are forcing industries to increase the use of water-soluble systems or to invest in various forms of emission control and cleaning systems.

\subsection{Air-Drying Coatings}

Air-drying coatings dry through evaporation of the solvent/water. These include cellulose-based lacquers, where the drying time can be sharply reduced by heating and good ventilation.

\subsection{Reaction-Curing Coatings}

In this group of coatings, the curing process is triggered by a chemical reaction. In many cases, reaction-curing finishes are two- or multi-component products.

\subsubsection{Acid-Curing Systems}

Acid-curing systems are based mainly on alkyd and amino (urea or melamine) resins, often combined with nitrocellulose. The acid component, the hardener, is a catalyst that starts and maintains the binder's curing process until the chemical reaction is complete. The solvent evaporates prior to and during the chemical reaction, and plays no part in the final film. The curing of acid-curing coatings can be dramatically accelerated by applying heat. In most respects, acid-curing coatings offer the optimal combination of required properties, i.e. they combine a competitive price per unit area with high durability, rapid throughput and an uncomplicated production process. They can also be combined with "mild" solvents and have a relatively high dry solids content. A disadvantage is a limited release of formaldehyde in connection with the curing process.

\subsubsection{Unsaturated Polyester Coatings}

In unsaturated polyester coatings, a cobalt catalyst and peroxide hardener are added to initiate and maintain the curing reaction. In this case, a solvent must also be added. This may be styrene that also functions as a reactive element in the coating system and is included in the final coating, or a conventional solvent that must first evaporate. Polyester resins offer several benefits, including a higher dry solids content combined with high reactivity. The disadvantages are a limited pot life and the fact that both hardener and catalyst require careful storage and handling. The pot life can 
be extended considerably by using mixing pumps that feature multi-component dosing, or curtain coaters with two wet-on-wet heads. In this case, the catalyst is mixed into the lacquer from the first head, while the hardener is mixed from the second.

\subsubsection{Polyurethane Coatings}

Polyurethane (PU) coatings are two-pack systems in which hydroxyl groups (the binder) react with isocyanate resin (the hardener). With pure PU coatings, applying heat does not appreciably accelerate the curing process. With blocked PU products, however, heat does accelerate the curing process. These types of product have been attracting renewed interest in many markets because of regulations covering formaldehyde-free processes. They offer a promising alternative to acid-curing lacquers, thanks to their rapid development in recent years, in combination with a sharp reduction in the previously high level of free isocyanate.

\subsubsection{UV-Curing Coatings}

UV lacquers are products that are cured by exposure to ultraviolet (UV) radiation in the wave length of 200-420 nm. They may be based on unsaturated polyesters, although acrylate-modified polyesters, PU or epoxy binders, are more common. These are also called pre-polymers. Polyester is often diluted with styrene, vinyl ether or an organic solvent. Acrylate pre-polymer is often diluted with a low viscosity binder. These are not volatile like an organic solvent, but form a film by cross-linking with the pre-polymer. A photoinitiator must be present to catalyse the cross-linking process. Its purpose is to transform UV radiation and initiate the curing process by means of a chain reaction. This curing process is very rapid. UV-curing products with a dry solids content of $100 \%$ are best suited to roller coating. Single-component pigmented UV-curing lacquers require UV lamps, known as "Ga-lamps", featuring a staggered wavelength area (400-420 nm). Otherwise, normal UV lamps (200-400 nm), known as "Hg-lamps", may be used. Designing a pigmented UV system for roller coating demands a thorough knowledge of the roller coater technique to achieve a superior finish. Combined systems with water-based primers and UV-curing products may be a more economically viable solution for some surface grades.

\subsubsection{Water-Based and UV-Curing Coatings}

Water-based UV-curing coatings can be one- or two-component systems, for clear or pigmented surface treatments. One-pack systems are the most common and are suitable in most situations and can replace most solvent-based systems (e.g. acid-curing or PU systems). To ensure proper curing of the edges when a one-pack 
system is used, UV ovens with inclined lamps must be used. The advantage of such a system, apart from the fact that it can be curtain coated or sprayed, is that once all the moisture has been removed and the UV curing has been completed, it produces a non-thermoplastic finish that is fully comparable with the high durability commonly associated with a conventional UV-curing system. Two-pack systems are used when extra high demands are placed on the finish or when inclined lamps are not available.

\subsection{Stains}

Stains are used to add colour to wood while revealing the texture of the substrate. They consist of colour and very finely dispersed transparent pigment, water, solvent and binder. Traditional stains mainly involved solvent-based stains, but in recent years water-based stains have been developed and they now dominate the market. Two factors in particular have contributed to this. Water-based stains make the texture of the wood surface appear more consistent and there are obvious environmental gains.

\subsection{Wood Surface Treatment with Oils and Waxes}

\subsubsection{Oils}

Oil has a strong, penetrating effect on wood, varying according to the structure of the substrate. How the wood has been prepared has a dramatic effect on the amount of oil the wood absorbs. A solid but unevenly grown piece of wood will exhibit very different absorption characteristics and may give the oiled surface a blotchy appearance. Normally, the surface must be dried and perhaps sanded again before the next layer of oil can be applied. Oil can be lightly tinted to function both as a stain and surface protection. In this case, a smoothly sanded surface with consistent absorption characteristics is critical. Add no more than 2-3\% of tinting paste, to avoid smearing. Solvent-free oils are ideal for the industrial finishing of pine and other wood species. All oiled surfaces require periodic aftertreatment to retain their protective properties.

Oils used for the treatment of wood are generally mixtures of various oils, and they may include alkyd, resin, balsam and solvents, formulated to give the product specific properties with respect to its use and/or price. Oils for the surface treatment of wood come mainly from the plant world, but animal oils and mineral oils also occur.

\subsubsection{Waxes}

Waxes are normally classified as "cold waxes" and "hot waxes". Cold waxes are usually water-based but they are not always completely solvent-free. They are also 
colourless, but can be tinted to provide an attractive "stain-like" appearance. An opaque finish can be achieved by multi-layer waxing, as can special effects (metallic, etc.) and plain finishes. Hot wax finishes require a special type of application equipment and they generally provide better protection than cold waxing. Hot wax can also be tinted but this involves a much more complex process, as a result of which the entire hot wax container acquires the same tint, making it very difficult to clean. Even after hot waxing, the product still requires regular care.

\subsection{New Surface Treatment Systems with Nanotechnology}

The development of new surface treatments for wooden materials for, e.g. outdoor use is a continuous process. One region in which intensive research and development activities are in progress is that of so-called nanotechnology-based surface treatment. Nanotechnology is an innovative generic field of technology which is rapidly developing, where nanoscience can be briefly described as the study and understanding of the properties of materials and underlying phenomena at the nanometre level $\left(1-100 \times 10^{-9} \mathrm{~m}\right)$. Within nanotechnology, nanomaterials are being developed with completely new properties compared with those of traditional materials. It is a question of building up structures with special functional properties at the nanometre level and of utilizing these for the development of new materials, new components and new systems. Applied nanotechnology appears to have an extremely large development potential and most progress has so far been made in the fields of material technology and medical applications.

Many surface treatment products based on nanotechnology are now commercially available with an ability to produce surfaces which repel dirt and water and prevent the growth of algae, fungi and mosses, with an improved UV- and temperature-resistance, better colour permanence, greater scratch- and abrasion resistance, anti-graffiti properties, and insulating properties and which are even more environment-friendly than the traditional surface treatment products. If all these new nanotechnology-based products live up to their marketing promises, they will in the not too distant future lead to a revolution in the surface treatment of, e.g. external wooden façades.

Most of the products are, however, new and in many cases there are still unanswered questions relating to their long-term performance and technical lifetime, their maintenance and thus the total economy seen in a life cycle perspective for the product or system of which the surface treatment is only a small part. Most nanotechnology-based surface treatment systems currently on the market are intended for mineral substrates and few of them can be recommended for the surface treatment of outdoor wood. Nevertheless, a lot of development work is in progress and it is believed that it will be possible to modify many of the surface treatment products based on nanotechnology which are currently being used on mineral substrates so that they can also be used on outdoor wood. 


\subsubsection{Nanotechnology for the Surface Treatment of Wood}

Surface treatments based on nanotechnology are currently available primarily for the treatment of substrates of an inorganic nature, such as metals, concrete, plaster, etc., which have the common feature that movements due to moisture or temperature variations are small. With wood as the substrate, the conditions and demands for a surface treatment system to function in a satisfactory manner are however different. This is probably the reason why it is more difficult to develop surface treatment products intended for wood. In the case of wood, the focus has been on surface treatment for use in an outdoor environment, rather than on, e.g. for house façades, for which it is more difficult to produce robust surface treatment systems.

In principle, nanotechnology offers an opportunity to produce composite materials with properties which can unite the special characteristics and advantages of different traditional materials. It is possible for instance to combine hardness with elasticity, good moisture protection with a high water vapour permeability, and good adhesion to the substrate with an ability to repel dirt and prevent microbial growth on the surface. With nanotechnology, it is also possible to achieve a surface coating to better protect the substrate against both climate-related and chemical environmental factors. Properties of a wooden façade which can be achieved by utilizing nanotechnology are:

- Surfaces which repel dirt and water

- Surfaces which hinder the growth of algae, fungi and mosses

- Surfaces which reduce moisture transport through end-grain sections

- Surfaces with a stronger resistance to UV radiation and temperature

- Surfaces with a better colour fastness

- Surfaces with a better resistance to scratching and abrasion

- Surfaces with more environment-friendly properties

- Surfaces which are anti-graffiti-treated

- Surfaces which reduce heat losses

The products available to make a surface dirt repellent or to hinder or prevent the growth of mould, fungi and algae can function according to several different "nanotechnological" principles. One principle is a treatment which makes the surface strongly water-repellent or "superhydrophobic", so that any water on the surface exists in the form of almost completely spherical drops. Particles of dirt or water-soluble contaminants can thus be transported away from the surface when the water drops run-off the surface. Another principle is to employ a treatment which makes the surface strongly hydrophilic at the same time as the treatment itself acts as a barrier to prevent water from penetrating into the substrate. The advantage in this case is that any water is retained as a thin homogeneous film which can run off the surface and dry without leaving any residual contamination. The third principle is to use photochemically active nanoparticles in the surface coating, e.g. a photochemically active form of titanium dioxide, which through photocatalysis can break down organic contaminants on the surface. The products resulting from the degradation by photocatalysis of contaminants on the surface are washed off by 
rain. A disadvantage of using photochemically active titanium dioxide particles for decontamination is however that if the binder contains organic components these will also be degraded by photocatalysis. This may make the method unsuitable for the surface treatment of wood.

If the surface of, e.g. a wooden façade could be made dirt repellent and able to prevent undesirable growth, the maintenance costs would be lowered be reducing or perhaps completely eliminating the need for façade cleansing. This property is already available for window glass.

Nanotechnology also offers the possibility of achieving a surface coating which can protect the wood substrate from ageing to a greater extent than traditional paints. In most of the information material relating to surface treatment products based on nanotechnology which are currently available on the market for use on outdoor wood, better weatherproofness and better colour fastness are mentioned as clear advantages over the traditional paint systems.

\subsubsection{Paint Systems on the Market Based on Nanotechnology}

The paint systems based on nanotechnology which are currently available on the market are here briefly described. Several of the systems are based on the so-called lotus effect, i.e. the self-cleaning mechanism found on the leaves of the lotus flower, the mechanism of which was first described and developed by the botanists Wilhelm Barthlott and Christoph Neinhuis at Bonn University in Germany (Barthlott and Ehler 1977; Barthlott and Neinhuis 1997; Neinhuis and Barthlott 1997). Superhydrophobic surfaces are extremely difficult to wet and the contact angle of water on such a surface is greater than $150^{\circ}$ and the run-off angle is less than $10^{\circ}$.

Any dirt on the leaves of the Lotus flower rapidly disappears when it rains. The water drops roll over the leaf, apparently without any friction and remove at the same time any dirt particles which have collected on the surface of the leaf. Electron micrographs show that the surface of the lotus leaf has a mixed micro/nanostructure built up of waxed papillae covered with hair-like nano-sized tubes, Fig. 18. This double structure captures air beneath the rain drops which fall onto the leaf and creates a surface which effectively repels the water. A wax is secreted as a thin layer on the papillae which in turn lift up the water drops so that the dirt runs off the leaf. The adhesion between the dirt particles and the leaf is extremely low. Experimental studies of the lotus effect have focussed mainly on how drops with a diameter of the order of a millimetre behave when they contact the surface of the leaf.

The lotus concept was introduced when Wilhelm Barthelot entered into a cooperation with the company Sto Corp., as a result of which a Bionic ${ }^{1}$ technology was developed to produce a synthetic surface with properties similar to those of the

\footnotetext{
${ }^{1}$ The word bionic is based on the Greek Biov, bion, which means life. Bionics is the application of systems found in nature to modern technology.
} 

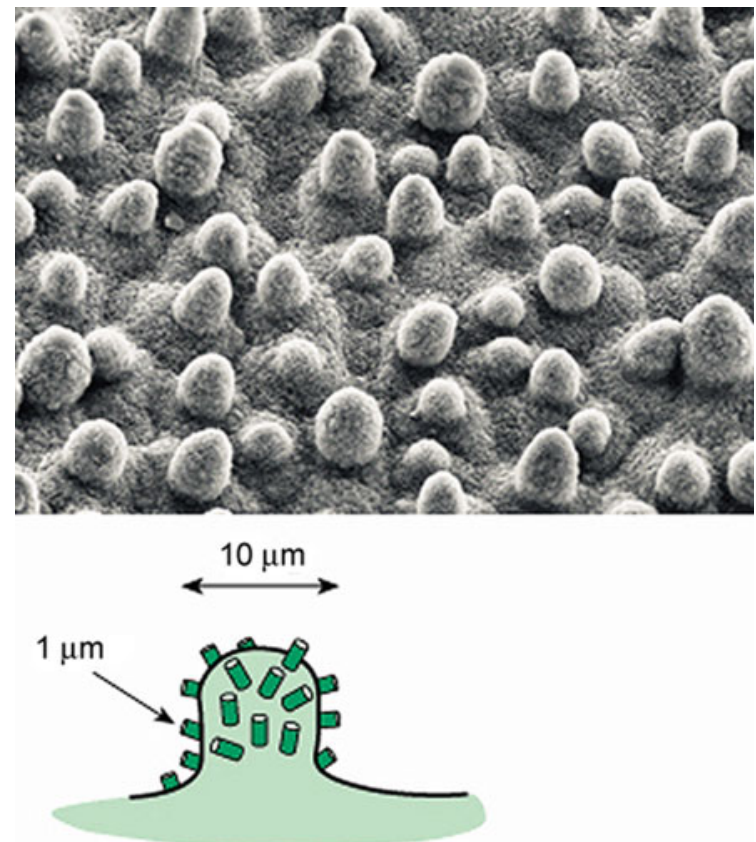

Fig. 18 The surface of the leaf of the lotus flower consists of small papillae covered with hair-like tubes

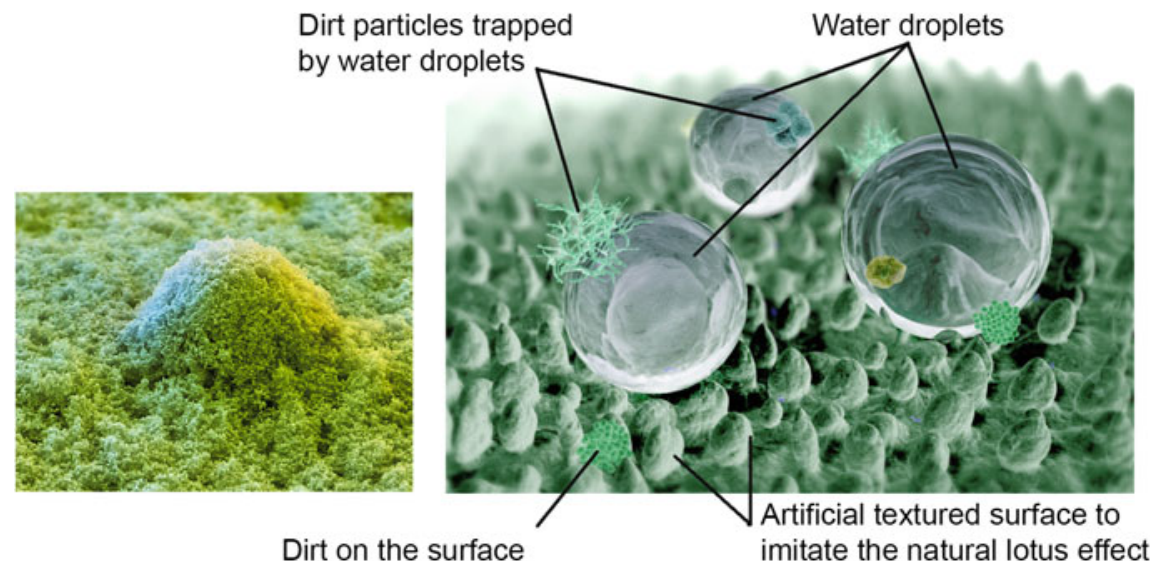

Fig. 19 Left Micrograph of a surface treated with a self-cleaning paint (ca. 10,000x magnification). Right Illustration of the mechanism for self-cleaning according to the lotus effect

lotus leaf and thus a surface which was dirt repellent, Fig. 19. The paint, which was introduced onto the market in 1999, is intended primarily for façades with a mineral substrate. There are a large number of references showing that the paint functions as 
intended all over the world. For the painting of outdoor wood, StoCoat Lotusan 215, 216 and 216D have been developed and they are recommended for use on wood which has been treated with a primer. The product is said to give a surface which is extremely hydrophobic, has an extraordinary ability to reject dirt and an improved resistance to moulds and algae. The paint is water-based and permeable to water vapour with exceptional colour fastness. A surface painted with two coats is guaranteed to have a lifetime of between 10 and 15 years.

Nanoseal Wood is an agent for impregnating wood based on nanotechnology, which makes the wood surface strongly water-repellent (www.nanoprotect.co.nz/ nanoseal-wood.htm). According to the manufacturer, the water-repellent effect is achieved through structural changes to the surface to a depth of $25 \mathrm{~nm}$. As a result of the treatment, the contact angle for water is as large as $120^{\circ}$ so that water runs off the surface instead of penetrating into the wood substrate. The treatment also has a UV-protecting effect.

As a result of the treatment, dirt particles cannot penetrate into the wood and all dirt is therefore washed off by rain or can easily be washed off mechanically. According to the manufacturer of Nanoseal Wood, the product gives a wood surface which is water-repellent, dirt-repellent, mould-resistant, self-cleaning and resistant to weather and UV radiation. According to the manufacturer, the product can be used on painted surfaces and on a new wood substrate provided the substrate is first aged. No information is available concerning its lifetime and how a new surface treatment should be carried out. The product was launched onto the market in 2005 by an Australian company.

NanoWood is, according to the manufacturer a multifunctional water-based silane for the surface treatment of untreated wood surfaces (www.nanoprotect.co. uk/wood-protection.html). Nanowood gives wood and stained wood water- and oil-repellent properties and is very similar to Nanoseal Wood in that a tight cross-linked network is created which, according to the manufacturer, is chemically bonded to the substrate. The product gives a strong and efficient protection against weather and wind, micro-organisms and moisture for up to 4 years.

According to the manufacturer, the advantages of the product are that it is dirtand water-repellent, that the wood substrate remains permeable to water, that drops of water on the surface dissolve and wash away water-soluble contamination on the surface, that it is transparent so that the texture and colour of the wood are still visible, that it is easy to clean, that it protects against UV and that it reduces the growth of algae, moulds and moss. The product is recommended for the surface treatment of wooden structures such as fences, façades and garden furniture, etc. A product with similar characteristics is marketed by the company Paint Protection Systems (http://www.paintprotectionsystems.com/wood-paints.asp).

The German paint company Caparol has developed a dirt-repellent façade paint AmphiSilan NQG with the aid of nanotechnology, where they try to combine the benefits of silicone paints and silicate paints. This gives a paint with both a strong water-repellent effect and good adhesion to the substrate.

AmphiSilan NQG utilizes the so-called NQG technology which employs nanoparticles of quartz which, together with "acrylate tendons" acting as bridges 
between particles, create a three-dimensional network. The paint gives a strong, shape-stable and nanostructured surface on which it is difficult for foreign particles to fasten. The harder the surface of the paint, the smaller is the amount of dirt which can be retained. If in addition the surface can be rinsed with water which can rapidly dry, at the same time as the penetration of water into the underlying substrate is hindered, the conditions for achieving a clean surface are ideal according to the manufacturer.

The nano-structured surface ensures that rain rapidly forms a very thin film of water which wets the whole surface and gives a thorough cleaning and a rapid drying of the treated wood surface. The appearance is, according to the manufacturer, not spoilt by any patches or streaks from water drops which have dried up or run across the surface. The NQG technique is a further development of the Caparol Clean Concept, which utilizes capillary hydrophobia and photocatalysis and has already been a success for Caparol. Capillary hydrophobia ensures that moisture can easily pass out through the paint layer, while the water-repellent silicone resin layer prevents water from passing in. The combination of the NQG technique and the Caparol Clean Concept gives AmphiSilan NQG a self-cleaning surface. Rainwater does not penetrate through the coating layer, whereas water vapour inside the wood is able to pass out. AmphiSilan NQG also contains photoactive titanium dioxide which breaks down contaminants which cannot be washed away by rainwater. Titanium dioxide has a photocatalytic effect which begins when titanium dioxide reacts photochemically, stimulated by the UV radiation in sunlight. AmphiSilan NQG is recommended for use on well-anchored previously painted substrates such as façades and also on structures of concrete, light-weight concrete, well-bound plaster and cement board. For external wooden façades, the CARAT oil-based paint system utilizes the NQG technique.

Herbol-Symbiotec is a façade paint which is the result of many year's development cooperation between Akzo Nobel and BASF (www.azonano.com/news). The product is based on nanotechnology and the use of the binder Col.9 which has been developed by BASF.

Col.9 is a new type of binder which is a nanocomposite hybrid with organic and inorganic components, Fig. 20, giving a binder combining the properties typical of both inorganic and organic binders. After drying, Col.9 consists of a soft inorganic plastic polymer matrix containing evenly distributed hard inorganic nanoparticles of quartz in a three-dimensional network, where the organic polymer matrix acts as an adhesive.

Col.9 gives a good balance, providing moisture protection together with a sufficiently high moisture vapour permeability. In contrast to the brittle mineral-based coatings, Col.9-based coatings have little tendency to crack. They can also withstand high temperatures and, because of their high silicon content, the coatings have little tendency to develop thermoplastic stickiness. The mineral particles give the coating a hydrophilic surface on which raindrops immediately spread. From a cleaning point of view, this has two advantages: in heavy rain dirt particles are easily washed away from the surface, and the thin moisture film rapidly dries, which inhibits mould growth. Col.9 exhibits a relatively good colour fastness and 

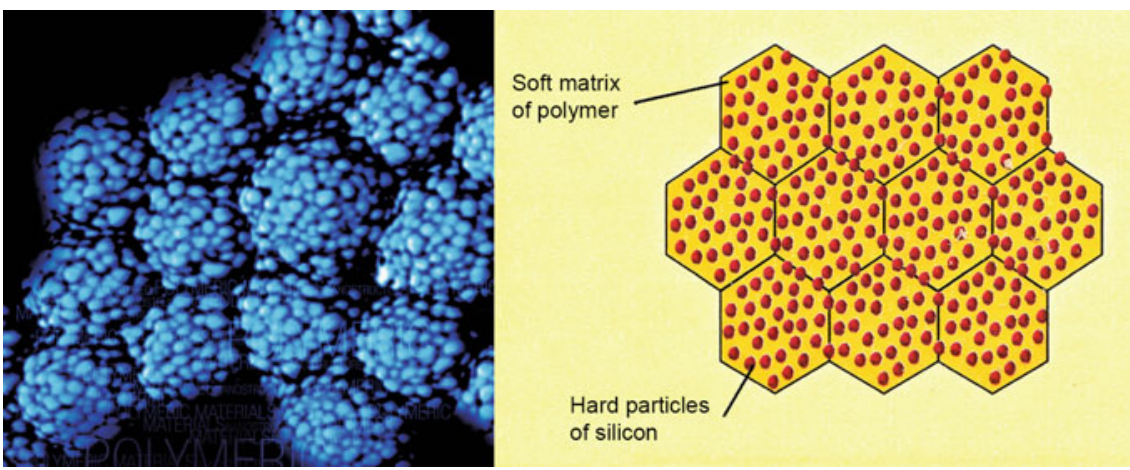

Fig. 20 Col.9 is a nanocomposite binder consisting of $10-20 \mathrm{~nm}$ silicon particles in a soft organic polymer matrix

weather resistance. The coating also contains additives which provide protection against mould growth.

The nanotechnology which Col.9 represents is now also being utilized in the development of a paint for the outdoor protection of wood. BASF reports that new binders have been developed with dirt-repellent and sufficient water protection in combination with high water vapour permeability. The first prototype paint for window frames was introduced in 2009.

Recently, various new Silicon-based products have entered the market. One example is OrganoWood (www.organoclick.com) that is a surface treatment technique which utilizes silicon molecules to give a wood surface which is more rot-resistant and more resistant to fire. Wood treated with OrganoWood is not classified as hazardous waste and this makes recycling much easier. The product is transparent and does not greatly affect the natural colour of the wood, which means that the timber retains its natural colour but ages and develops a greyish colour with time.

\subsection{Environmental Aspects of Coatings}

When working with paints and lacquers, a user can be exposed in various ways to potential health risks; inhalation of fumes from evaporating solvents, spray mist or dust from sanding of lacquer that is not fully cured or direct contact with liquid paints and lacquers during handling, either via the skin or eyes.

The most obvious and best-known risk associated with working with paints and lacquers is the threat posed by overexposure to solvents. For this reason, it is important to adopt protective measures in the form of sealed systems and ventilation/air cleaning systems, and to use personal protection, such as various types of masks. Substances other than solvents can also pose a health risk upon inhalation. You should therefore 
check the health risks stated on the labels when using a product (i.e. warning symbols and risk phrases). The initial effect of inhaling large quantities of organic solvents is a form of inebriation that causes impaired judgement, retarded reactions, clumsiness and tiredness. Extended exposure to concentrated solvent emissions can result in chronic damage to the liver, kidneys and brain. However, not all solvents are equally dangerous. Some of the solvents that pose the greatest danger are aromatic solvents, such as toluene and xylene. To ensure safety at work, public authorities cooperate with medical experts on a continual basis, to determine Occupational Exposure Standards for substances that can be dangerous if inhaled. The legal requirements vary from country to country. Most countries apply limit values (occupational exposure limits) to the substances. These limit values are often expressed as averages over specified time periods, e.g. $8 \mathrm{~h}$ or $15 \mathrm{~min}$. Sometimes the limit values must not be exceeded, sometimes they must be observed only if they are technically and economically reasonable. Air pollutants consist of a combination of different substances. Exposure readings taken at the place of work are based on all the substances present in the air, after which the additive hygienic effect can be assessed. The additive hygienic effect (HE) can be summarized: $\mathrm{HE}=\mathrm{C} 1 / \mathrm{L} 1+\mathrm{C} 2 / \mathrm{L} 2+\mathrm{C} 3 / \mathrm{L} 3$, where $\mathrm{C} 1, \mathrm{C} 2, \mathrm{C} 3$ are the observed concentrations of substances 1, 2, 3, etc., and L1, L2, L3 are the occupational exposures limit values (OEL values) of these same substances (expressed in the same units). In most countries the HE value must be less than 1 to be acceptable.

In recent years, the risks posed by the inhalation of various types of dust have attracted increasing attention. Such risks are associated primarily with dust that is respirable, i.e. dust particles that are so small that they can penetrate deep into the lungs. The afflictions that can arise, such as asthma or cancer, can be caused by a number of different factors. In some cases, the condition is the result of a toxic reaction, when particles are partially or completely dissolved in the lungs. In other cases, damage to the lungs may derive from a strictly physical injury (e.g. silicosis). Sometimes, health may be damaged when other substances attach themselves to the surface of inhaled particles, and therefore remain trapped in the lungs longer than if they had simply been inhaled in a gaseous form. It is therefore important to protect oneself against overintense exposure to dust, of whatever type. The lists of occupational exposure limits state general hygienic limits for dust and define specific limits for a number of special substances.

A brief description of the labelling system for health and environmental warnings on paints and lacquers is given in Table 5. The most common warning symbols together with risk phrases (R-phrases) are described. Although other symbols and $\mathrm{R}$-phrases exist, these are seldom used for paints and lacquers in the wood finishing industry.

Environmental analyses of wood coatings are complicated. Since currently acceptable LCA methodology leaves ample room for estimates and assumptions that may vary from one practitioner to another, subtle variations in techniques and data sources influence the coating manufacturers' calculations of the life cycles of their products, making it essential to use appropriate techniques to compare their results with each other. Different companies also seem to favour different ways of generating impact scores, such as by weighting VOC emission data by 
Table 5 Labelling system for health and environmental warnings on paints and lacquers

\begin{tabular}{|c|c|c|}
\hline Toxicity level & R-phrases & Description \\
\hline Very toxic/toxic & $\mathrm{R} 26$ & Very toxic by inhalation \\
\hline \multirow{7}{*}{ Very Toxic } & $\mathrm{R} 27$ & Very toxic in contact with skin \\
\hline & $\mathrm{R} 28$ & Very toxic if swallowed \\
\hline & $\mathrm{R} 23$ & Toxic by inhalation \\
\hline & $\mathrm{R} 24$ & Toxic in contact with skin \\
\hline & $\mathrm{R} 25$ & Toxic if swallowed \\
\hline & R39 & Danger of very serious irreversible effects \\
\hline & $\mathrm{R} 48$ & $\begin{array}{l}\text { Danger of serious damage to health by prolonged } \\
\text { exposure }\end{array}$ \\
\hline \multirow[t]{2}{*}{ Carcinogenic } & $\mathrm{R} 45$ & May cause cancer \\
\hline & $\mathrm{R} 49$ & May cause cancer by inhalation \\
\hline Mutagenic & $\mathrm{R} 46$ & May cause hereditary genetic damage \\
\hline \multirow{2}{*}{$\begin{array}{l}\text { Toxic for } \\
\text { reproduction }\end{array}$} & R60 & May impair fertility \\
\hline & R61 & May cause harm to the unborn child \\
\hline \multirow[t]{6}{*}{ Harmful } & $\mathrm{R} 20$ & Harmful by inhalation \\
\hline & $\mathrm{R} 21$ & Harmful in contact with skin \\
\hline & $\mathrm{R} 22$ & Harmful if swallowed \\
\hline & $\mathrm{R} 42$ & May cause sensitization by inhalation \\
\hline & $\mathrm{R} 48$ & $\begin{array}{l}\text { Danger of serious damage to health through prolonged } \\
\text { exposure }\end{array}$ \\
\hline & R65 & May cause lung damage if inhaled \\
\hline Carcinogenic & $\mathrm{R} 40$ & Possible risk of irreversible effects \\
\hline Mutagenic & R68 & Possible risk of irreversible effects \\
\hline \multirow{2}{*}{$\begin{array}{l}\text { Harmful for } \\
\text { reproduction }\end{array}$} & R62 & Possible risk of impaired fertility \\
\hline & R63 & Possible risk of harm to the unborn child \\
\hline
\end{tabular}

photochemical reactivity rather than reporting raw emissions data, further complicating comparisons. One of the challenges encountered is in the data on emission impacts associated with the extraction and refining of natural resources to create some of the raw materials (pigments, additives, etc.). Some help can be achieved from a project carried out in US to develop a platform for accurately accounting for the life cycle impacts of paint and coatings from raw material extraction through to end-of-life (Anon 2011).

\section{Aspects on Additives in Waste Wood for Combustion}

Wood and wood-based products have unique end-of-life properties. In addition to the recycling of by-products like sawdust, chips and offcuts into particleboard, many other panel products are manufactured from recycled wood. However, beyond this, wood is increasingly being used as a substitute for fossil fuels, 
providing a renewable energy source which simply returns to the atmosphere the $\mathrm{CO}_{2}$ it originally removed. Cascading enhances the efficiency of resource utilization by a sequential re-utilization of the same unit of a resource for multiple high-grade material applications followed by a final use for energy conversion (Sirkin and ten Houten 1994). Primary raw materials are thus saved and positive effects due to the substitution of finite materials by renewable resources can be increased (Gustavsson and Sathre 2011). For the recycling of wood and wood fibres it is important that the components, i.e. chemicals or other materials, added to wood in the different process stages do not prevent the use of the wood in the next cycle or prevent the return of the ash to the natural life cycle.

Recovered wood fuel is wood material which has previously had another use and which is to be burned, usually in an energy conversion plant (SIS 2009). It can consist of e.g. demolition wood, shuttering wood, packaging wood or spillage from renovation and new constructions, and it is one component of the wider category of biofuels, which includes liquors from the pulp industry, peat, recycled waste paper, straw, etc.

Recovered wood fuel is generally designated recycled waste wood or, when the material is in a finely divided (chipped) state, chipped recycled waste wood. Recycled wood need not be used solely as a source of energy in a heat-producing plant. It can also be reused or recovered through other processes, e.g. for the manufacture of charcoal. In countries where it is forbidden to use organic waste as landfill (e.g. in Sweden since 2005), there are in principle only two ways of recovering waste wood material (Sundqvist et al. 2009). One is to re-use the material in some type of structure and the other is to use it to produce energy through combustion. According to Tullin and Jermer (1998), approximately half of all recycled waste wood can be reused for building purposes, while the remainder should be used for energy conversion. Most of the installations which utilize recycled chipped waste for energy conversion use a mixed fuel with other solid fuels. The fuel mix usually contains $10-40 \%$ of chipped waste, but there are also plants which use $100 \%$ chipped waste wood (Andersson and Tullin 1999).

\subsection{Recycling of Wood}

The increasing scarceness of primary raw materials leads to a greater focus on secondary resources. Deposits from urban infrastructure, mainly the building stock, are potentially a major secondary resource. Höglmeier et al. (2013) analysed the amounts of wood incorporated in the building stock of south-east Germany, and calculated resulting streams of recovered wood in order to quantify potentially available volumes for an environmentally beneficial cascading utilization of these secondary resources. They found that considerable amounts of recovered wood in a condition suitable for a resource-efficient use in cascades can be expected to originate from the building stock: $26 \%$ of the recovered wood is suitable for reuse and $27 \%$ could be channelled into other high-value secondary applications. 
In several European countries, recycled waste wood is not only free from energy and carbon dioxide taxes but also qualifies for an electricity certificate, which means that recycled waste wood is relatively in demand as a fuel. On the other hand, it makes greater demands on the plant which burns recycled waste wood than on a plant which uses only wood fuel directly from silvicultural raw material (so-called virgin wood fuel), and this means that many choose not to use recycled waste wood in their fuel mix (Strömberg 2005). In the long term, when the demand for recyclable ash for the nutritional compensation of e.g. forest land increases, a fuel mix containing recycled waste wood may be less and less attractive, since the ash from the combustion of recycled waste wood usually contains substances which must not be spread in nature.

A major problem in the recovery of energy from recycled waste wood is that some of the material has been treated in some way, e.g. impregnated with a wood preservative or subjected to a surface treatment. Nor is it unusual for other structural components of, e.g. plastic or metal to accompany the recycled waste wood (Tullin and Jermer 1998; Strömberg 2005). The contamination in recycled waste wood can be divided into chemical contaminants derived from, e.g. paint and impregnating materials, and mechanical contaminants such as plastic, fittings, glass, nails and screws (Jermer et al. 2001; Strömberg 2005). Mechanical contaminants are in general easier to deal with than chemical contaminants, since they can be separated from the recycled waste wood before combustion either at the demolition site or in subsequent handling (waste sorting), but this usually leads to increased costs.

The contaminants in the recycled waste wood vary strongly depending on the type of wood recovered and also on how it is handled in connection with demolition, sorting and chipping. The chemical contaminants may include, e.g. potassium, chlorine, sodium, zinc and lead if paints or other surface treatments have been used. Other possible contaminants are copper, chromium and arsenic if the wood has been impregnated with a wood preservative (Andersson and Tullin 1999). According to e.g. Jermer et al. (2001), most of the chemical contaminants can be found in the fine fraction of the material obtained after chipping, and this means that it is therefore possible to separate much of the contamination from the purer fractions. Since the fine fraction can amount to 25-40 per cent by weight of the chips this may mean, however, that a large fraction of the chipped waste wood must then be dealt with in some other way, e.g. by deposition as landfill.

The chipped recycled waste wood is characterized by a high ash content, up to ca. $25 \%$ has been reported, and a moisture content of 20-35\% (Andersson and Tullin 1999), and the ash from the chipped waste contains large amounts of heavy metals (Tullin and Jermer 1998). In addition, the nitrogen and chlorine contents are in certain cases slightly higher in recycled waste wood than in virgin wood fuel (Berg et al. 2003). Nitrogen influences the combustion process negatively with regard to e.g. discharges. There is a risk that chlorine in combination with certain metals, particularly copper, may lead to the formation of dioxins. Dioxins are a joint name for ca. 200 chlorine-containing substances which may give rise to cancer, foetal damage, infertility and various skin diseases (The National Encyclopaedia 2015). 
The combustion of chipped recycled waste wood involves more engineering problems than the combustion of virgin wood fuel. The risk of coating and corrosion in the combustion chamber of the recovery boiler increases with high contents of zinc and chlorine (Berg et al. 2003; Strömberg 2005). In boilers with a fluidized bed, it is primarily the ash feed out and the bottom nozzles which become clogged when the ash fuses together. In grate-fired boilers, the problem is that the air vents in the grate become clogged because the metals in the fine fraction melt at the high temperatures which arise locally on the grate. According to Strömberg (2005), it is better to burn chipped waste wood in a boiler with a fluidized bed than in a grate-fired boiler because the coatings in the digester as well as the flue ash contain much less zinc when a fluidized bed is used. By increasing the sulphur and silicate content in the combustion, the problem can be further reduced.

The use of recycled waste wood as fuel makes high demands on the exhaust gas cleaning in the plant, particularly the equipment for particle separation, to fulfil the increasingly strict emission regulations. With regard to heavy metals in the flue gas, any differences between various fuel assortments are due chiefly to differences in the efficiency of the particle separation equipment at the plant (Andersson and Tullin 1999). The main problem is that heavy metals are enriched in the ash. According to measurements reported by Berg et al. (2003), the emission limits regarding metals from boilers are met if the regulations regarding particle separation are complied with. This is because heavy metals such as arsenic, cadmium, lead and zinc are enriched in the fly ash particles which are separated from the flue gases.

The discharge of hydrochloric acid and sulphur dioxide is somewhat higher in the combustion of chipped recycled waste wood than in the combustion of virgin wood fuel. The discharge of gaseous substances is, however, more difficult to remedy, since this requires flue gas treatment in addition to particle removal. Conventional flue gas condensation is often sufficient to reduce the discharge of hydrochloric acid, but further steps are needed to meet the requirements regarding sulphur dioxide.

To meet the increasingly restrictive emission limits in many European countries in the incineration of CCA-impregnated wood, both flue gas condensation and an efficient particle removal are required (Sundqvist et al. 2009). In the combustion of wood impregnated with modern copper-based wood preservatives, it is, however, sufficient if the combustion unit is equipped with an electrostatic precipitator.

\subsubsection{Chemical Contaminants in Recycled Waste Wood Due to Surface Treatment}

Surface treatments such as varnish, paint and mould or rot inhibitors are the most common contaminants in recycled waste wood, and since these compounds are enriched in the ashes from the combustion of the recycled waste wood, these ashes should not be returned to the natural eco-cycle but should instead be deposited or taken care of in some other way. 
When wood is impregnated with a wood preservative or is surface treated in some way, both organic and inorganic substances are introduced into the wood, but it is primarily the inorganic substances which lead to problems in the combustion process since they are retained in the ashes, the fly ashes and the flue gases, while the organic substances are degraded by the combustion (Tullin and Jermer 1998). If flue gas cleansing is incorporated into the combustion plant, most of the inorganic contaminants will finally end up in the ashes and this will reduce the possibility of returning the ashes to the natural eco-cycle.

Paints consist primarily of binder, solvent, pigment and various additives such as siccatives, fillers and fungicides and some these additives can lower the melting point of the ashes and thus increase the risk of coating and clogging in the boiler.

The binders in the paint normally cause few problems in combustion since they are usually organic compounds consisting primarily of carbon, hydrogen and oxygen, but there are exceptions. Protein-based binders contain nitrogen and they thus increase the content of "fuel nitrogen" which leads to increased problems with the emission of nitrogen oxides $\left(\mathrm{NO}_{\mathrm{x}}\right)$. Some varnishes also contain both nitrogen and sulphur and this leads to increased amounts of $\mathrm{NO}_{\mathrm{x}}$ and $\mathrm{SO}_{2}$ in the flue gases.

The solvents in modern paints are in general not a problem, since they are either water-based or organic. Older types of paint can, however, contain chlorine-based solvents and these can lead to an increased content of chlorine in the combustion of chipped recycled waste wood, but the content should not be particularly high since the solvents in paints normally evaporate when the paint dries.

Pigments can be divided into two categories, viz. organic and inorganic. Of these, it is the inorganic pigments which are of greatest concern since they contain oxides of metals such as zinc, titanium, chromium, iron and in some cases also lead. Certain inorganic pigments also contain nitrogen. The main causes of problems in organic pigments are nitrogen and chlorine, but some so-called organic pigments also contain metals such as copper and chromium. The presence of nitrogen leads to the emission of $\mathrm{NO}_{\mathrm{x}}$, and chlorine in the fuel contributes to the formation of hydrochloric acid and dioxins during combustion.

Of the various paint additives, the siccatives are the most interesting from a contaminant viewpoint since they may contain heavy metals, the most common being zinc, calcium, lead, iron, manganese, lithium, barium and cobalt. Fillers can contain calcium, silicon, aluminium, magnesium and barium. Together with alkali metals, silicon can form compounds which melt at a low temperature. Water-based paints must also be $\mathrm{pH}$-adjusted since they otherwise tend to be too acidic. Sodium hydroxide is used for this purpose, and this introduces sodium which can be a problem in the combustion plant.

\subsubsection{Chemical Contaminants in Recycled Waste Wood as a Result of Impregnation}

Previously, the substances predominantly used for the impregnation of wood were CCA, which contaminates the wood with primarily chromium, copper and arsenic, 
and creosote. Until the middle of the 1990s, CCA was the dominant substance for the impregnation of sawn wood, but its use in EU has since been forbidden for use above ground and CCA has been replaced by water-based copper-containing wood preservatives (Sundqvist et al. 2009). The contaminants in these agents are mainly copper, nitrogen and chlorine. Between 1975 and 1995, most of the wooden window frames made in Sweden were impregnated with a preservative containing organic tin compounds, Nowadays, wooden window frames are impregnated with triazoles which are organic compounds containing nitrogen and chlorine.

Creosote is a distillate obtained from coal tar and it is organic in nature which means that creosote-impregnated timber is well suited for combustion (Tullin and Jermer 1998; Jermer et al. 2001). Apart from the fact that creosote is derived from a fossil material, it is similar to normal wood fuel from an environmental point of view. Creosote is used mainly for the impregnation of railway sleepers and telegraph poles. Creosote predominates as a wood preservative for sleepers, and it is only very rarely that sleepers are impregnated with any other preservative agent (Jermer et al. 2001). In the future, a long-term environmental adaptation of wood preservative substances will be necessary so that wood impregnated with preservatives can be recycled with the smallest possible effect on the environment.

\subsubsection{Chemical Contamination Due to Other Additives}

In addition to substances for surface treatment and impregnation, a number of other additives used in the manufacture of wood products will be present in recycled waste wood and may give rise to problems in the combustion process. These are primarily the glues used in various structural elements (glued-laminated timber) and in board materials such as MDF, plywood and particleboards. Nitrogen, sulphur and chlorine are important components in many adhesives. As previously stated, nitrogen leads to the emission of $\mathrm{NO}_{\mathrm{x}}$, sulphur to the emission of $\mathrm{SO}_{2}$ and chlorine in combination with certain catalytic metals, particularly copper, gives rise to dioxins.

\subsection{The Need for Recycled Waste Wood in Heat-Generating Plants}

Chipped recycled waste wood is an excellent fuel for energy recovery as long as the plant has sufficient flue gas cleansing and provided the ash is handled correctly. The ash can in some cases be used to cover landfill if the limiting value for heavy metals is not exceeded.

The quality demands for recycled waste wood that is to be incinerated are similar within European countries, but they vary from country to country. All combustion plants generally wish to have waste wood sorted at source without plastic, metal or surface treatment and with a small fine fraction. In certain countries (e.g. Sweden) 
a special licence is required for the combustion of CCA-impregnated timber, but the restrictions are milder in the case of modern preservatives and such recycled timber can be incinerated in most plants. Increasing energy requirements, stricter EU-directives for the classification of fuel waste, and increasing deposition taxes are expected to lead to a greater demand for recycled waste wood sorted at source and to a greater need for methods for the quality assurance of waste wood. If recycled waste wood is to be incinerated in normal combustion plants and not in special installations, a sorting at source of the raw material at the point of demolition is necessary, and this is not normally the case in, e.g. Sweden. In Germany, sorting at source of the waste wood is very common and impregnated and painted waste wood is incinerated in special plants while the clean waste wood material is incinerated in conventional biofuel boilers. It is not therefore uncommon in Germany for chipped waste wood to have a content of contaminants at the same low level as virgin wood fuel (Berg et al. 2003).

The ash from incinerated recycled waste wood that contains surface-treated, impregnated or otherwise contaminated wood must, as already mentioned, not be returned to nature because of its content of heavy metals. In order to be able to return the ash from the combustion of recycled waste wood, the waste wood must be sorted at source so that the clean chipped waste wood can be incinerated in a conventional plant, while the impregnated and surface-treated wood is incinerated in a special plant with sufficient flue gas cleansing, after which the ash can be deposited as landfill.

Sorting at source can take place either at the demolition site or through a fractionation of the recycled waste wood so that the fine fraction containing most of the contamination can be separated. The fine fraction is then incinerated in a plant which has a licence to do so. Since large quantities of the contaminants which lead to problems in the boiler are present in the fine fraction, the methods for fractionation of the waste wood could be adapted so that a large part of this fraction can be separated from the chipped waste wood.

\section{Concluding Remarks}

Today, forestry and forestry-related industries are sharply in the focus of discussions concerning the major challenges for the future. A great challenge for humankind is to develop a sustainable society. Such a society requires the use of renewable materials, a large reduction in the use of non-renewable natural resources and a large reduction in environmental impacts, including a drastic reduction of greenhouse gas emissions. This includes methods and resources used in industry, construction and consumer products, including those made from wood.

One way of reducing the emission of carbon dioxide is to use a larger proportion of wood products and to increase the lifetime of these products so that the carbon is stored over a longer period of time. Another possibility is to replace energy-intensive materials with wood and wood-based products. Forest resources 
and wood products can, therefore, play an important role in a long-term strategy for sustainable development and lessen man's impact on the environment. Replacing non-renewable materials with wood-based ones is hence crucial for the development of a sustainable society, and new knowledge is required to show how resource-efficient processes for wood products with a low environmental impact can be designed and implemented.

Although sawn timber and wood-based products remain vital from an economic and utilitarian standpoint, it is increasingly essential that the technology to create EWPs from wood and other renewable resources be understood, applied and further developed. In the future, wood products also have to be refined so that all the life cycle phases - production, operation, retrofitting and end-of-life-are considered and optimized as a whole, including the energy and material chains from forest to final services.

Wood is to a great extent combined with additives to achieve a more efficient use of the wood resource. Additives from renewable resources have a great potential in the future, due not only to environmental concerns but also to the anticipated future scarcity of petroleum and petroleum-based products, but economic and durability questions have to be solved. Bio-based adhesives already have a commercial and industrial impact in, e.g. plywood and particleboard production, and the adhesive is never more than $10 \%$ by weight of the whole composite panel. This is sufficient to conform to the performance and costs required by the wood panel industry and their respective product standards. Additives from renewable resources may in the future have the greatest potential over other additives because of their easiness in reusing, recycling and recovery for energy conversion.

\section{References}

Andersson C, Tullin C (1999) Förbränning av returflis - kvalitetssäkring och drifteserfarenheter (The combustion of recycled wood - quality assurance and operational experiences), Report No 668. Thermal Engineering Research Association (Värmeforsk), Stockholm

Anon (2011) Life cycle assessment of volatile organic compounds (LCA-VOC) in paints \& coatings: final report. National Center for Manufacturing Sciences Inc, Ann Arbor

Barthlott W, Ehler N (1977) Raster-Elektronenmikroskopie der Epidermis-Oberflächen von Spermatophyten (Scanning electron microscopy of the epidermal surfaces of spermatophytes). Tropische und subtropische Pflanzenwelt 19:110 (Akad Wiss Lit Mainz). Franz Steiner Verlag, Mainz

Barthlott W, Neinhuis C (1997) Purity of the sacred lotus, or escape from contamination in biological surfaces. Planta 202(1):1-8

Berg M, Andersson A, Andersson C et al (2003) Förbränning av returträflis - Etapp 2 av ramprojekt returträflis (Combustion of recovered wood-stage 2 of the framework project recovered wood), Report No 820. Thermal Engineering Research Association (Värmeforsk), Stockholm

Berger J (2006) Bauplatte oder der gleichen, deren herstellung und werwendung (Building panel or the like, and production and use thereof). PCT Patent PCT/AT2006/000141, 6 Apr 2006

Bobacz D (2002) In CNC-Technik gefertigte zimmermannsmäßige Verbindungsmittel: Untersuchung des Schwalbenschwanzzapfens. Diplomarbeit, Universität für Bodenkultur, Vienna 
Boonstra MJ, Pizzi A, Zomers F et al (2006) The effects of a two stage heat treatment process on the properties of particleboard. Holz Roh Werkst 64(2):157-164

Bourgois J, Guyonnet R (1988) Characterisation and analysis of torrefied wood. Wood Sci Technol 22:143-155

Carrasco F, Roy C (1992) Kinetic study of dilute-acid prehydrolysis of xylan-containing biomass. Wood Sci Technol 26:189-208

Carus M, Gahle C (2008) Injection moulding with natural fibres. Reinf Plast 52(4):18-25

CEN (1992) EN-120, Wood-based panels. Determination of formaldehyde content: extraction method (called the perforator method). European Community for Standardization (CEN), Brussels

CEN (2007) CEN/TS 15679, Thermal modified timber-definitions and characteristics. European Community for Standardization (CEN), Brussels

CEN (2013) EN-301, Adhesives, phenolic and aminoplastic, for load-bearing timber structuresclassification and performance requirements. European Community for Standardization (CEN), Brussels

Clemons CM (2002) Wood-plastic composites in the United States - the interfacing of two industries. Forest Prod J 52(6):10-18

Dagher HJ, Bragdon MM, Lindyberg RF (2002) Advanced fiber-reinforced polymer-wood composites in transportation applications. Transp Res Rec 1814:237-242

Detlefsen WD (2002) Phenolic resins: some chemistry, technology and history. In: Chaudhury MK, Pocius AV (eds) Adhesive science and engineering: surfaces, chemistry and applications. Elsevier, Amsterdam (chap. 20)

DIBt (2012) Allgemeine bauaufsichtliche Zulassung DIBT Z-9.1-649 für SchwalbenschwanzVerbindung in Bauteilen (General building inspection approval DIBt Z-9.1-649 for dovetail joint in components). Deutsche Institut für Bautechnik, Berlin

Dietrichs HH, Sinner H, Puls J (1978) Potential of steaming hardwoods and straw for feed and food production. Holzforschung 32:193-199

Dietsch P (2005) Development of a finite-element model for parameter studies of a dovetail connection. Diplomarbeit, Fachgebiet Holzbau, Technische Universität, München

DIN (1979) DIN Standard 7707: types of resin impregnated and compressed laminated wood and insulating wood. Deutsches Institut für Normung

Dunky M (2003) Adhesives in the wood industry. In: Pizzi A, Mittal KL (eds) Handbook of adhesive technology. Marcel Dekker, New York (chap. 47)

Ek M, Gellerstedt G, Henriksson G (eds) (2000) Pulp and paper chemistry and technology, vol 15. Walter de Gruyter GmbH \& Co, Berlin

Ellis S, Paszner L (1994) Activated self-bonding of wood and agricultural residues. Holzforschung 48:82-90

Feifel S, Poganietz WR, Schebek L (2013) The utilization of light weight boards for reducing air emissions by the German wood industry - a perspective? Environ Sci Eur 25(5). doi:10.1186/ 2190-4715-25-5

Frihart CR (2011) Wood adhesives. Vital for producing most wood products. For Prod J 61(1):4-12

Frihart CR, Birkeland MJ (2014) Soy properties and soy wood adhesives. In: Brentin RP (ed) Soy-based chemicals and materials. ACS Sym Ser 1178, American Chemical Society, Washington, DC, pp 167-192

Frybort S, Mauritz R, Teschinger A, Müller U (2008) Cement bonded composites-a mechanical review. BioResources 3(29):602-626

Fuch W (1928) Genuine lignin. I. Acetylation of pine wood. Ber Dtsch Chem Ges 61B:948-951

Geimer RL, Leao A, Armbruster D, Pablo A (1994) Property enhancement of wood composites using gas injection. In: Maloney TM (ed) Proceedings of the 28th Washington State University International particleboard/composite materials symposium, April 12-14. Pullman, pp 243-259

Goldstein IS (1955) The impregnation of wood to impart resistance to alkali and acid. For Prod J 5:265-267 
González-García S, Feijoo G, Heathcote C, Kandelbauer A, Moreira M (2011) Environmental assessment of green hardboard production coupled with a laccase activating system. J Cleaner Prod 19(5):445-453

Graubner W (1992) Encyclopedia of wood joints. Taunton Press, Newtown

Gustavsson L, Madlener R, Hoen HF et al (2006) The role of timber material for greenhouse gas mitigation. Mitig Adapt Strat Glob Change 11(5/6):1097-1127

Gustavsson L, Sathre R (2011) Energy and $\mathrm{CO}_{2}$ analysis of wood substitution in construction. Clim Change 105(1/2):129-153

Haller P (2007) Concepts for textile reinforcements for timber structures. Mater Struct 40:107-118

Haller P, Wehsener J, Werner TE, Hartig J (2013a) Recent advancements for the application of moulded wooden tubes as structural elements. In: Aicher S, Reinhard HW, Garrecht H (eds) Material and joints in timber structures. Springer, Heidelberg, pp 99-108

Haller P, Putzger R, Wehsener J et al (2013b) Formholzrohre - Stand der Forschung und Anwendungen (Molded wood pipes - state of research and applications). Bautechnik 90:34-41

Hallström S (1995) Glass fibre reinforcement around holes in laminated timber beams. Department of lightweight Structures, Report No 95-14. Royal Institute of Technology, KTH, Stockholm

Hein PRG, Aparecida de Sá V, Bufalino L et al (2009) Calibrations based on near infrared spectroscopic data to estimate wood-cement panel properties. BioResources 4(4):1620-1634

Hillis WE (1975) The role of wood characteristics in high temperature drying. J Inst Wood Sci 7:60-67

Hochstrate M (2000) Untersuchungen zum Tragverhalten von CNC gefertigten Schwalbenschwanzverbindungen (Investigations on the structural behavior of CNC crafted dovetail joints). FH Hildesheim/Holzminden/Göttingen, Hildesheim

Holzner H (1999) Entwicklung eines Nachweisverfahrens zur Bemessung von speziellen (maschinell gefertigten) Zapfenverbindungen (Development of a detection method for the design of special (machine-made) mortise and tenon joints). Institut für Tragwerksbau-Fachgebiet Holzbau, Technische Universität Münich, Germany

Hood EE, Nelson P, Powell R (eds) (2011) Plant biomass conversion. Wiley-Blackwell, West Sussex

Horn O (1928) Acetylation of beech wood. B Dtsch Chem Ges 61B:2542-2545

Höglmeier K, Weber-Blaschke G, Richter K (2013) Potentials for cascading of recovered wood from building deconstruction: a case study for south-east Germany. Resour Con Recy 78:81-91

IEC (2006) IEC Standard No 61061-1, Non-impregnated densified laminated wood for electrical purposes-part 1: definitions, designation and general requirements. International Electrotechnical Commission, Geneva

Insulander R (1997) The Fenno-Urgian two-wood bow-a missing link. Bull Primitive Technol 14(2):35-39

Jermer J, Ekvall A, Tullin C (2001) Inventering av föroreningar i returträ (Inventory of pollutants in recycled wood). Report No 732, Thermal Engineering Research Association (Värmeforsk), Stockholm

Kamdem DP, Pizzi A, Triboulot MC (2000) Heat-treated timber: potentially toxic by-products presence and extent of wood cell degradation. Holz Roh Werkst 58(4):253-257

Kamke FA (2013) THM - a technology platform or novelty product? In: Medved S, Kutnar A (eds) Characterization of modified wood in relation to wood bonding and coating performance. Proceedings of the COST FP0904 and FP1003 International Workshop, Rogla, 16-18 Oct 2013

Killen G (2000) Wood-procurement and primary processing. In: Nicholson PT, Shaw I (eds) Ancient Egyptian materials and technology. Cambridge University Press, Cambridge, pp 353-368

Kitek Kuzman M, Kutnar A (2014) Contemporary Slovenian timber architecture for sustainability. Green energy and technology. Springer, Berlin, p 163 
Klauditz W, Stegmann G (1955) Beiträge zur Kenntnis des Ablaufes und der Wirkung thermischer Reaktionen bei der Bildung von Holzwerkstoffen (Contributions to the knowledge of the sequence and the effect of thermal reactions in the formation of wood materials). Holz Roh Werkst 13:434-440

Klyosov AA (2007) Wood-plastic composites. Wiley-Interscience, Hoboken

Knight EV, Wulpi M (eds) (1927) Veneers and plywood. Their craftmanship and artistry, modern production methods and present-day utility. The Ronald Press Company, New York

Koehler A, Pillow MY (1925) Effect of high temperatures on the mode of fracture of a softwood. Southern Lumberman 121:219-221

Kollmann FFP, Kuenzi EW, Stamm AJ (1975) Principles of wood science and technology II. Wood based materials. Springer, New York

Kreuzinger H, Spengler R (1999) Zum Tragverhalten von maschinell abgebundenen Zapfenverbindungen aus Konstruktionsvollholz zwischen Haupt-und Nebenträger (For structural behavior of machined hardened tenon joints from construction timber between the main and secondary beams). Untersuchungsbericht LKI, 7313, Technische Universität Münich, Germany

Kuroki Y, Nagatomi W, Yamada J (1993) Manufacture of light-weight cement-bonded particleboard. In: Moslemi AA (ed) 3rd International inorganic-bonded wood and fiber composite materials conference, Spokane 28-30 Sept 1992

Kutnar A, Burnard MD (2014) The past, present, and future of EU wood adhesive research and market. In: International conference on wood adhesives. Toronto, 9-11 Oct 2014

Kutnar A, Hill C (2014) Assessment of carbon footprinting in the wood industry. In: Muthu SS (ed) Assessment of carbon footprint in different industrial sectors, vol 2., EcoProductionSpringer, Berlin, pp 135-172

Kutnar A, Sandberg D, Haller P (2015) Compressed and moulded wood from processing to products. Holzforschung 69(7):885-897

Lande S, Westin M, Schneider M (2004) Properties of furfurylated wood. Scand J For Res 19 (5):22-30

Lauer JP (1933) Fouilles du service des antiquités à saqqarah (secteur nord, Novembre 1932-mai 1933). (Excavations of the Department of Antiquities at Saqqara (north sector, November 1932-May 1933)). Annales du service des antiquités de L'Égypte 33:155-166

Li K, Peshkova S, Gen X (2004) Investigation of soy protein-kymene ${ }^{\circledR}$ adhesive systems for wood composites. J Am Oil Chem Soc 81:487-491

Linné Cv (1737) Flora Lapponica (The flora of Lapland). Schouten, Amsterdam

Lopez-Anido R, Xu H (2002) Structural characterization of hybrid FRP-glulam panels for bridge decks. J Compos Constr ASCE 6(3):194-203

Lopez-Anido R, Michael AP, Sandford TC (2003) Experimental characterization of FRP composite-wood pile structural response by bending tests. Mar Struct 16(4):257-274

Lopez-Anido R, Muszynski L, Gardner DJ, Goodell B, Herzog B (2005) Performance-based material evaluation of fiber-reinforced polymer-wood interfaces in reinforced glulam members. J Test Eval 33(6):385-394

Lucas A (1936) The wood of the third dynasty, ply-wood coffin from Saqqara. Annales du service des antiquités de L'Égypte 36:1-4

Mahapatra K, Gustavsson L (2008) Multi-storey timber buildings: breaking industry path dependency. Build Res Inf 36(6):638-648

Maloney TM (1977) Modern particleboard and dry-process fibreboard manufacturing. Miller-Freeman Publications, San Francisco

Navi P, Sandberg D (2012) Thermo-hydro-mechanical processing of wood. EPFL Press, Lausanne

Neinhuis C, Barthlott W (1997) Characterization and distribution of water-repellent, self-cleaning plant surfaces. Ann Bot 79(6):667-677

Näsström J (2005) Stjärnsågning igen - Nystart i mindre skala och med ny teknik (Star-Sawing again —a restart on a smaller scale and with new technology). Nordisk träteknik Såg \& Trä 9:12-13

Phleps H (1982) The craft of log building. Lee Valley Tools Limited, Ottawa 
Pizzi A (2006) Recent developments in eco-efficient bio-based adhesives for wood bonding: opportunities and issues. J Adhes Sci Techn 20(8):829-846

Pizzi A, Mittal KL (2003) Handbook of adhesive technology. Marcel Dekker, New York, p 672

Pokharel N (2003) Behaviour and design of sandwich panels subject to load buckling and flexural wrinkling effects. PhD thesis, School of Civil Engineering, Queensland University of Technology

Rebstock F, Bomark P, Sandberg D (2015) Makerjoint, a new concept for joining members in timber engineering - strength test and failure analyses. Pro Ligno 11(4):397-404

Richter K (2001) LCA—reuse/recycle. In: Johansson CJ, Pizzi T, van Leemput M (eds) Wood adhesion and glued products, Report on the state of the art of COST Action E13, pp 161-180

Robeller C, Mayencourt P, Weinand Y (2014a) Snap-fit joints-CNC fabricated, integrated mechanical attachment for structural wood panels. In: ACADIA 2014 design agency: Proceedings of the 34th annual conference of the association for computer aided design in architecture. Los Angeles, 23-25 Oct 2014, Riverside Architectural Press, pp 189-198

Robeller C, Hahn B, Mayencourt P, Weinand Y (2014b) CNC-gefräste Schwalbenschanzzinken für die Verbindung von vorgefertigten Bauteilen aus Brettsperrholz (CNC machined dovetail joints for the connection of prefabricated components made of laminated timber). Bauingenieur 89:487-490

Rowell RM (2005) Handbook of wood chemistry and wood composites. Taylor \& Francis, Boca Raton

Rowell RM, Simonson R, Tillman AM (1986) A simplified procedure for acetylation of chips for dimensionally stabilized particleboard products. Pap Puu 68(10):740-744

Sandberg D, Haller P, Navi P (2013) Thermo-hydro and thermo-hydro-mechanical wood processing: an opportunity for future environmentally friendly wood products. Wood Mat Sci Eng 8(1):64-88

Savastano Júnior H, Warden PG, Coutts RSP (2000) Brazilian waste fibers as reinforcement of cement-based composites. Cement Concr Compos 22(25):379-384

Schefferus J (1673) Lapponia. ex officina Christiani Wolffii, Frankfurt am Main, Germany (See also translation by John Scheffer (1674). The history of Lapland, Oxford)

Schindler C (2009) Ein architektonisches Periodisierungsmodell anhand fertigungstechnischer Kriterien, dargestellt am Beispiel des Holzbaus (An architectural periodization based production engineering criteria, using the example of timber construction). Eidgenössische Technische Hochschule Zürich, ETH, Zürich

Shade N (1998) The strip-built sea kayak. Ragged Mountain Press, Camden

Sirkin T, ten Houten M (1994) The cascade chain: a theory and tool for achieving resource sustainability with application for product design. Resour Con Recy 10:213-277

SIS (2009) SS 187106: Fasta biobränslen och torvbränslen - Terminologi (Solid boifules and peat fuels-Terminology). Swedish Standards Institute, Stockholm

Skuratov N (2010) New lightweight solid wood panels for green building. In: Proceedings of the International convention of society of wood science and technology and United Nations Economic Commission for Europe-Timber Committee, Geneva, 11-14 Oct 2010

Sonti SS, GangaRao HVS (1996) Banding timber crossties using composite fabrics for improving their performance. Materials for the new technology. ASCE Press, Washington, DC, pp 14491457

Stamm AJ, Seborg RM (1939) Resin-treated wood. Ind Eng Chem 31:897-992

Stamm AJ, Burr HK, Kline AA (1946) Staybwood. Heat-stabilized wood. Ind Eng Chem 38:630 634

Stevens WC, Turner N (1970) Wood bending handbook. HMSO, London

Strömberg B (2005) Bränslehandboken (Fuel Handbook). Report No 911, Thermal Engineering Research Association (Värmeforsk), Stockholm

Suchsland O, Woodson GE (1986) Fiberboard manufacturing practices in the United States. USDA Forest Service Agriculture Handbook, 640, US Government Printing Office, Washington, DC 
Suida H, Titsh H (1928) Chemistry of beech wood: acetylation of beech wood and cleavage of the acetyl-beech wood. Ber Dtsch Chem Ges 61B:1599-1604

Sundqvist JO, Erlandsson M, Solyom P, Högberg B, Bergman G (2009) Impregnerat trä i kretsloppet - rekommendationer för restprodukthantering (Chemical preservative wood in recycling-recommendations for waste management). Report No B1827, Swedish Environmental Research Institute IVL, Stockholm

Tarkow H, Stamm AJ, Erickson ECO (1946) Acetylated wood. Report No 1593, USDA, Forest Service, Forest Prod Lab, Madison

Tannert T, Prion H, Lam F (2007) Structural performance of rounded dovetail connections under different loading conditions. Can J Civ Eng 34(12):1600-1605

Tannert T, Lam F, Vallée T (2011) Structural performance of rounded dovetail connections: experimental and numerical investigations. Eur J Wood Wood Prod 69(3):471-482

Tiemann HD (1915) The effect of different methods of drying on the strength of wood. Lumber World Rev 28:19-20

The National Encyclopedia (2015) http://www.ne.se/dioxiner. Accessed 24 Aug 2015

Tullin C, Jermer J (1998) Inventering och energiutvinning av träskyddsbehandlat virke i Sverige (Inventory and energy of preservative-treated wood in Sweden). Report No 653, Thermal Engineering Research Association (Värmeforsk), Stockholm

Wallenberg FT, Bingham P (2010) Fiberglass and glass technology, energy-friendly compositions and applications. Springer Science+Business Media LLC, New York

Werner F, Richter K (2007) Wood building products in comparative LCA. A literature review. Int J Life Cycle Ass 12(7):470-479

Wilson TRC (1920) The effect of kiln drying on the strength of airplane woods. Report No 68, National Advisory Committee for Aeronautics, Washington, DC

Zwerger K (2012) Wood and wood joints: building traditions of Europe and Japan. Walter de Gruyter, Berlin 